Aus der Abteilung Neurogenetik

(Direktor Prof. Dr. K.-A. Nave)

des Max-Planck-Instituts für Experimentelle Medizin

in Göttingen

\title{
Therapie der Charcot-Marie-Tooth-Krankheit bei Ratten mittels einer phospholipidreichen Ernährung
}

\author{
INAUGURAL-DISSERTATION \\ zur Erlangung des Doktorgrades \\ für Zahnheilkunde \\ der Medizinischen Fakultät der \\ Georg-August-Universität zu Göttingen
}

vorgelegt von

Lennart Martin Rasch

aus

Eberbach

Göttingen 2021 
Dekan:

Betreuungsausschuss

Betreuer/in:

Ko-Betreuer/in:

\section{Prüfungskommission}

Referent/in:

Ko-Referent/in:

Drittreferent/in:
Prof. Dr. med. W. Brück

Prof. Dr. med. M. W. Sereda

Prof. Dr. med. S. Hülsmann

Prof. Dr. med. M. W. Sereda

Prof. Dr. med. S. Hülsmann

Prof. Dr. med. dent. R. Mausberg

Datum der mündlichen Prüfung: $\quad$ 24.06.2021 
Hiermit erkläre ich, die Dissertation mit dem Titel "Therapie der Charcot-Marie-Tooth-Krankheit bei Ratten mittels einer phospholipidreichen Ernährung" eigenständig angefertigt und keine anderen als die von mir angegebenen Quellen und Hilfsmittel verwendet zu haben.

Göttingen, den

(Unterschrift) 


\section{Inhaltsverzeichnis}

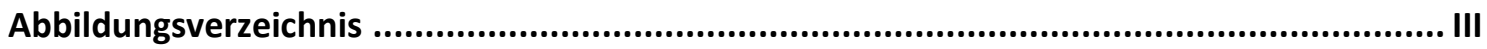

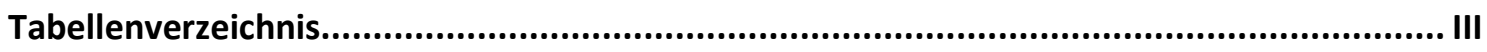

Zeichen- und Abkürzungsverzeichnis .........................................................................

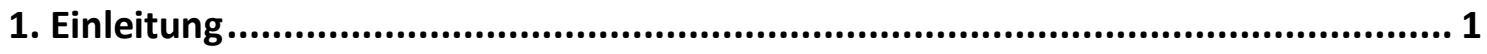

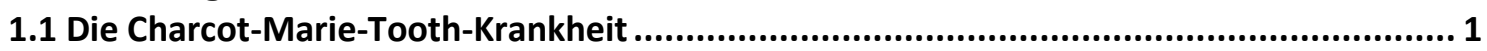

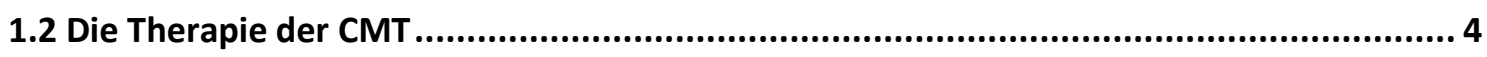

1.3 Experimentelle pharmakologische Therapiestrategien für die CMT ................................ 5

1.4 Experimentelle Therapiestudien mit phospholipidreicher Ernährung und Zielsetzung des

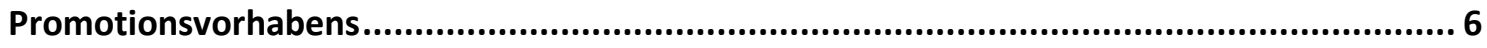

2. Material und Methoden ..................................................................................... 7

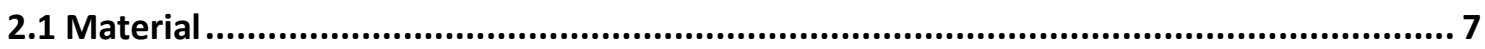

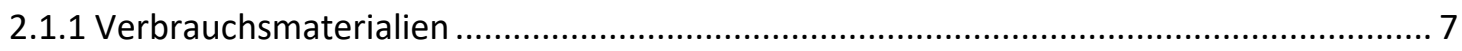

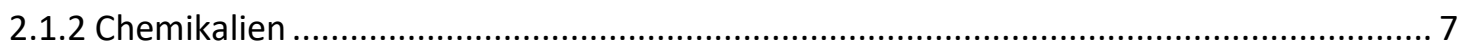

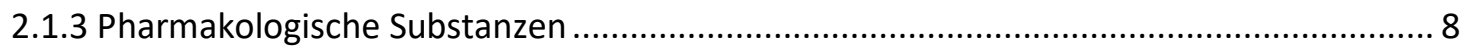

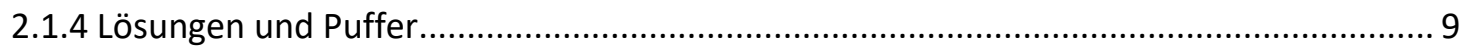

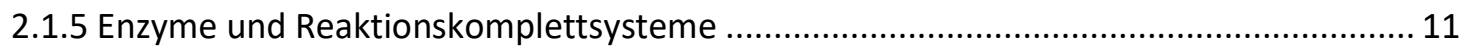

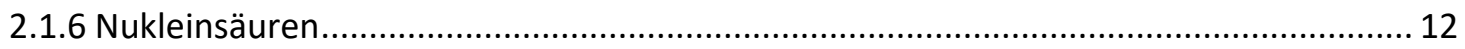

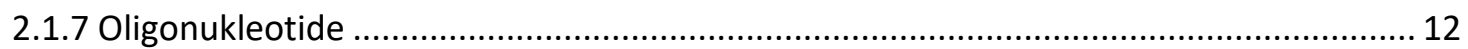

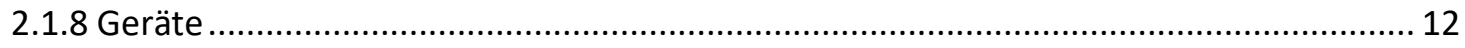

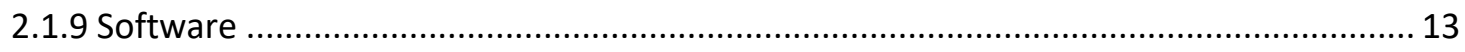

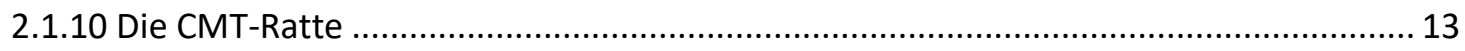

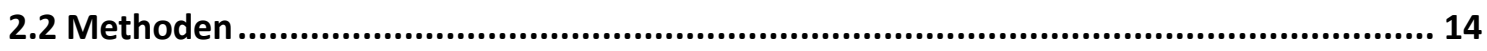

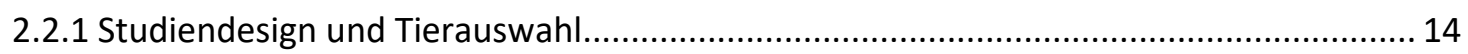

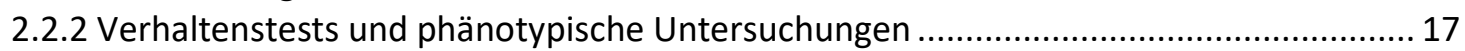

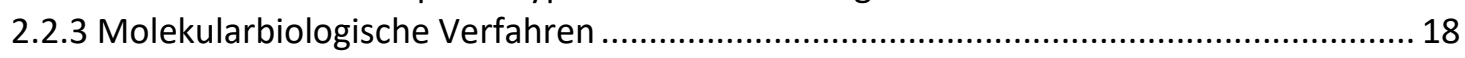

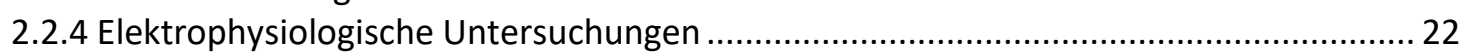

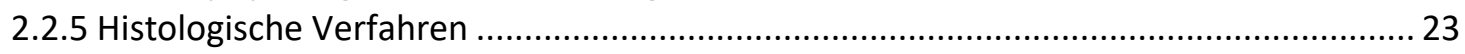

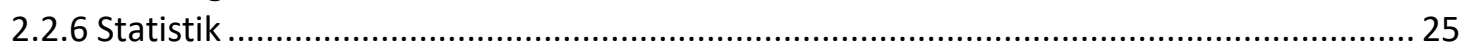

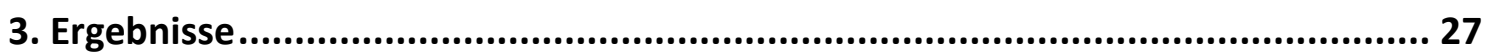

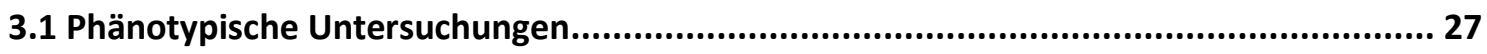

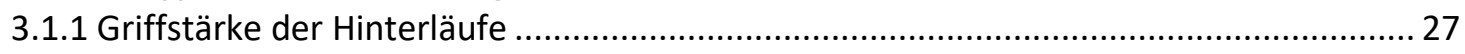

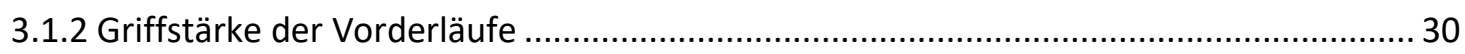

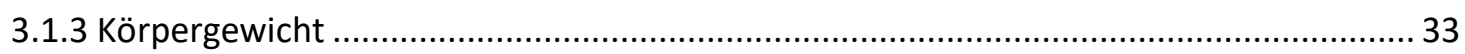

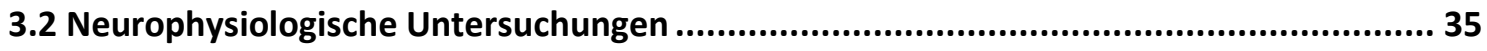

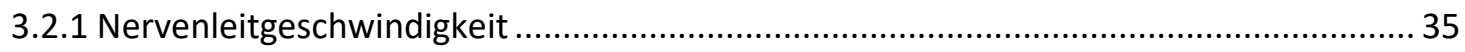

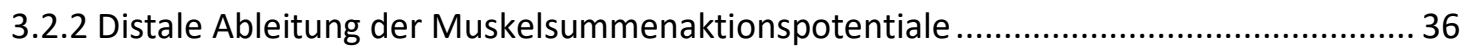

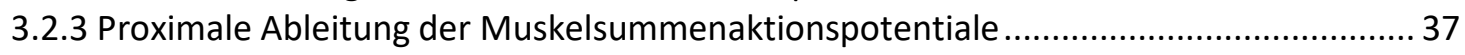

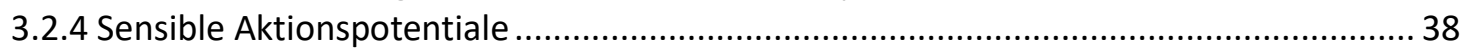

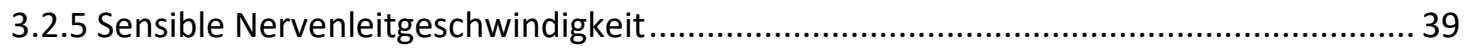

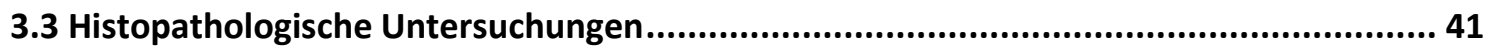

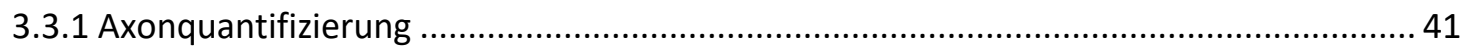

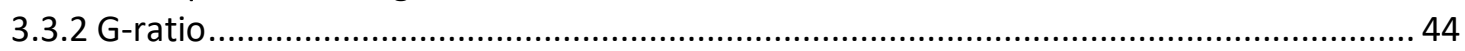

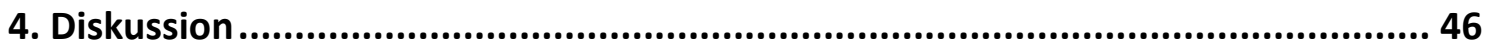

4.1 Das Ausmaß des Therapieerfolges ist vom Zeitpunkt der initialen Verabreichung und der verabreichten Dosis des L- $\alpha$-Phosphatidylcholin abhängig ................................................ 46 
Inhaltsverzeichnis

4.2 Hypothetische Überlegungen zum molekularen Wirkungsmechanismus von L- $\alpha-$ Phosphatidylcholin ... 49

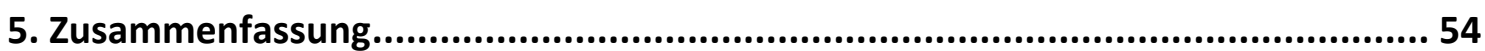

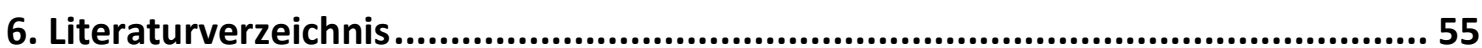




\section{Abbildungsverzeichnis}

Abb. 1: Klinische Symptomatik der CMT .................................................. 3

Abb. 2: Zeitlicher Ablauf der verschiedenen Therapiestudien ................... 14

Abb. 3: Messung der Griffstärke an Vorder- und Hinterläufen................... 17

Abb. 4: Verlaufsdiagramm zur Griffstärke der Hinterläufe ........................ 27

Abb. 5: Griffstärke der Hinterläufe zum jeweiligen Studienende .............. 28

Abb. 6: Verlaufsdiagramm zur Griffstärke der Vorderläufe ....................... 30

Abb. 7: Griffstärke der Vorderläufe zum jeweiligen Studienende ............. 31

Abb. 8: Verlaufsdiagramm zum Körpergewicht........................................ 33

Abb. 9: Körpergewicht zum jeweiligen Studienende ................................ 34

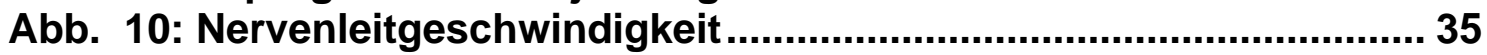

Abb. 11: Muskelsummenaktionspotential............................................... 36

Abb. 12: Proximale Ableitung der Muskelsummenaktionspotentiale....... 37

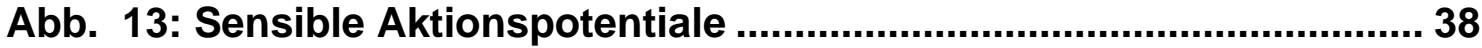

Abb. 14: Sensible Nervenleitgeschwindigkeit .......................................... 39

Abb. 15: Axonquantifizierung - später Therapiebeginn ............................41 4

Abb. 16: Axonquantifizierung - früher Therapiebeginn (Kurzzeitstudie). 42

Abb. 17: Axonquantifizierung - früher Therapiebeginn............................. 43

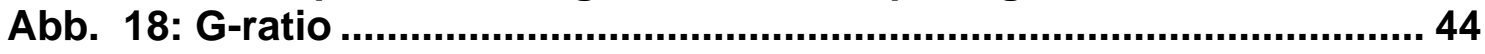

\section{Tabellenverzeichnis}

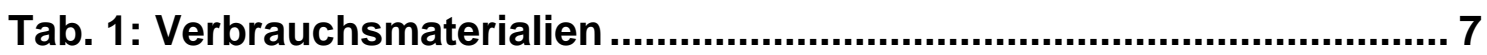

Tab. 2: Chemikalien ........................................................................................... 7

Tab. 3: Pharmakologische Substanzen..................................................... 8

Tab. 4: Zusammensetzung von phosphatgepuffertem Glutaraldehyd ........ 9

Tab. 5: Zusammensetzung der Gebrauchslösung zur Narkose.................... 9

Tab. 6: Zusammensetzung der Eponlösung A .......................................... 10

Tab. 7: Zusammensetzung der Eponlösung B ......................................... 10

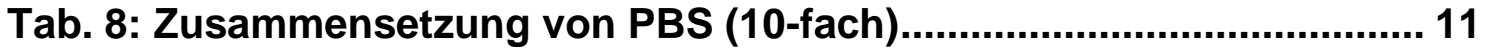

Tab. 9: Zusammensetzung des TAE-Puffers ............................................... 11

Tab. 10: Enzyme und Reaktionskomplettsysteme .................................. 11

Tab. 11: Nukleinsäuren ..................................................................................... 12

Tab. 12: Geräte .................................................................................................. 12

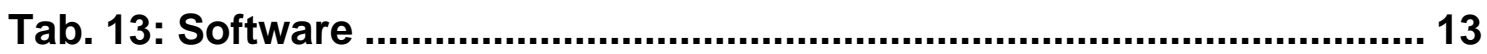

Tab. 14: Griffstärke Hinterläufe....................................................... 27

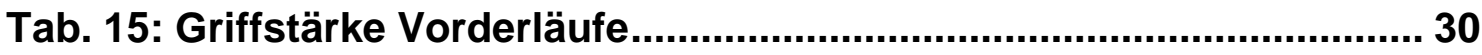

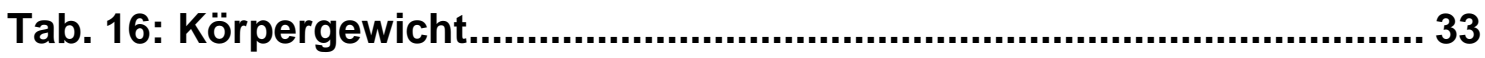




\section{Zeichen- und Abkürzungsverzeichnis}

\begin{tabular}{|c|c|}
\hline $\begin{array}{l}\text { Zeichen bzw. } \\
\text { Abkürzung }\end{array}$ & Bedeutung \\
\hline CMAP & $\begin{array}{l}\text { compound muscle action potential; Muskelsummenaktions- } \\
\text { potential }\end{array}$ \\
\hline CMT & Charcot-Marie-Tooth-Krankheit \\
\hline CMT1A & Charcot-Marie-Tooth-Krankheit Typ 1A \\
\hline CMT-Ratte & PMP22-transgenes Tiermodell \\
\hline CMTNS & Charcot-Marie-Tooth neuropathy score \\
\hline $\mathrm{ddH}_{2} \mathrm{O}$ & doppelt destilliertes Wasser \\
\hline DDSA & 2-Duodecenyl-succinicacidanhydrid \\
\hline $\mathrm{dH}_{2} \mathrm{O}$ & destilliertes Wasser \\
\hline DMP30 & 2,4,6-Tris(dimethylaminomethyl)phenol \\
\hline DNA & desoxyribonucleic acid; Desoxyribonukleinsäure \\
\hline dNTP & Desoxynucleosidtriphosphat \\
\hline EDTA & Ethylendiamintetraessigsäure \\
\hline Gew.-\% & Gewichtsprozent \\
\hline HDAC6-Inhibitoren & Inhibitoren der Histon-Deacetylase 6 \\
\hline HMSN1 & hereditäre motorisch-sensible Neuropathie Typ 1 \\
\hline KGaA & Kommanditgesellschaft auf Aktien \\
\hline M & molare Masse bzw. Molar \\
\hline MNA & Methylnadicanhydrid \\
\hline n.s. & nicht signifikant \\
\hline N. & Nervus; Nerv \\
\hline $\mathrm{NIH}$ & $\begin{array}{l}\text { National Institutes of Health; Nationale Gesundheitsinstitute } \\
\text { (der USA) }\end{array}$ \\
\hline NLG & Nervenleitgeschwindigkeit \\
\hline N. V. & naamloze vennootschap \\
\hline ONLS & Overall Neuropathy Limitations Scale \\
\hline $\mathrm{p}$ & p-Wert \\
\hline PBS & phosphate-buffered saline; phosphatgepufferte Salzlösung \\
\hline PCR & polymerase chain reaction; Polymerasekettenreaktion \\
\hline $\mathrm{pH}$ & $\begin{array}{l}\text { pondus Hydrogenii; pondus = Gewicht; Hydrogenium = } \\
\text { Wasserstoff }\end{array}$ \\
\hline PFA & Paraformaldehyd \\
\hline PLP & Proteolipid-Protein \\
\hline PMP22 & peripheres Myelinprotein $22 \mathrm{kDa}$ \\
\hline PXT-3003 & Kombination von Baclofen, Naltrexone und Sorbitol \\
\hline rpm & revolutions per minute; Umdrehungen pro Minute \\
\hline SNAP & sensory nerve action potential; sensible Aktionspotentiale \\
\hline SNCV & $\begin{array}{l}\text { sensory nerve conduction velocity; sensible Nervenleit- } \\
\text { geschwindigkeit }\end{array}$ \\
\hline TAE-Puffer & TRIS-Acetat-EDTA-Puffer \\
\hline Taq & Thermus aquaticus \\
\hline $\operatorname{tg}$ & transgen \\
\hline UV & ultraviolett \\
\hline wt $\%$ & percent by weight; Gewichtsprozent \\
\hline
\end{tabular}




\section{Einleitung}

\subsection{Die Charcot-Marie-Tooth-Krankheit}

Die Charcot-Marie-Tooth-Krankheit (CMT) zählt zu den heriditären Neuropathien und ist in der aktuellen klinischen Nomenklatur ebenfalls als heriditäre motorischsensible Neuropathie Typ 1 (HMSN1) bekannt.

Derzeit wird eine Vielzahl von Entitäten innerhalb der CMT unterschieden. Hierzu gehören die CMT1 und ihre Subformen: CMT1A, CMT1B, CMT1C, CMT1D, CMT1E und CMT1F; die CMT2 und ihre Subformen: CMT2A1, CMT2A2, CMT2B, СМт2B1, СМт2В2, СМт2C, СМт2D, CMT2E, CMT2F, CMT2G, CMT2H, CMT2I, СMT2J, CMT2K, CMT2L, СMT2M, CMT2N, CMT2O und CMT2P; die CMT3; die CMT4 und inre Subformen: CMT4A, CMT4B1, CMT4B2, CMT4B3, CMT4C, CMT4D, CMT4E, CMT4F, CMT4G, CMT4H, CMT4I und CMT4J; die CMT5; die CMT6; die CMTDI und ihre Subformen: CMTDIA, CMTDIB, CMTDIC, CMTDID und CMTDIE; die CMTRI und ihre Subformen: CMTRIA und CMTRIB; die CMTX und ihre Subformen: CMTX1, CMTX2, CMTX3, CMTX4 und CMTX5 (Szigeti und Lupski 2009).

Mit einer Prävalenz von ca. 4 pro 10.000 ist die Charcot-Marie-Tooth-Krankheit die häufigste hereditäre Neuropathie des Menschen. Der größte Subtyp dieser Erkrankung ist die CMT1A, welche zu den demyelinisierenden Polyneuropathien zählt.

Der der CMT1A zugrundeliegende Pathomechanismus basiert auf einer Duplikation des Gens für das periphere Myelinprotein 22 kDa (PMP22), welches auf dem Chromosom 17p11.2-p12 lokalisiert ist. Diese Duplikation hat zur Folge, dass das Gen für PMP22 bei erkrankten Individuen in dreifacher Kopie vorliegt anstatt in zweifacher Kopie, wie bei gesunden Individuen üblich. Infolge der beschriebenen Mutation kommt es zu einer Gendosiserhöhung von 50 Prozent und nachfolgenden Fehlfunktionen auf zellulärer und subzellulärer Ebene, 
welche eine für die betroffenen Schwannzellen spezifische Charakteristik aufweisen. Als Resultat dieser Fehlfunktionen kommt es in erster Instanz zu einer Demyelinisierung der Axone peripherer Nerven, die schließlich sekundär in einen axonalen Verlust mündet. Weiterhin führen diese Prozesse zu einer verminderten Innervation der nachgeschalteten Muskulatur, die sich letztlich als insbesondere die distale Muskulatur der Extremitäten betreffende Muskelatrophie äußert.

Die moderne Diagnostik der CMT1A basiert auf molekularbiologischen Verfahren, welche die Gendosiserhöhung infolge der Duplikation des PMP22Gens bereits im Kindesalter nachzuweisen vermögen.

Die CMT1A weist eine charakteristische Symptomatik auf. Typischerweise liegt eine chronisch fortschreitende Muskelatrophie vor, welche symmetrisch insbesondere die unteren Extremitäten betrifft und hierbei eine distale Betonung aufweist. Diese Form der Muskelatrophie führt letztlich dazu, dass die betroffenen Patienten motorische Behinderungen aufweisen, deren Ausprägung mit steigendem Alter zunimmt. Von Patient zu Patient variiert die Ausprägung der motorischen Behinderung und deckt ein Spektrum ab, welches von latenten Beeinträchtigungen beim Gehen bis hin zu einer Rollstuhlgebundenheit reicht. Ein Auftreten erster Symptome wird typischerweise bei einem durchschnittlichen Lebensalter der Patienten von etwa 20 Jahren beobachtet. Noch vor den motorischen Behinderungen können typische Fußdeformitäten und vermindert auslösbare Muskeleigenreflexe sowie Störungen der Sensibilität insbesondere distaler Extremitätenabschnitte festgestellt werden. Die bereits angesprochene Demyelinisierung der Axone peripherer Nerven, wie sie bei den demyelinisierenden Subformen der CMT auftritt, stellt das morphologische Korrelat einer auf unter $38 \mathrm{~m} / \mathrm{s}$ verringerten Nervenleitgeschwindigkeit (NLG) dar. Noch vor allen bereits geschilderten klinischen Symptomen kann eine solche verminderte NLG mittels neurophysiologischer Untersuchungsverfahren detektiert werden. Eine neurophysiologische Untersuchung fördert zudem verminderte Muskelsummenaktionspotentiale (CMAP) hervor, welche infolge des ebenfalls zuvor beschriebenen sekundären axonalen Verlusts auftreten. Die so 


\section{Einleitung}

verminderten CMAP stellen wiederrum das neurophysiologische Korrelat des Leitsymptoms der distal betonten Muskelatrophie dar.

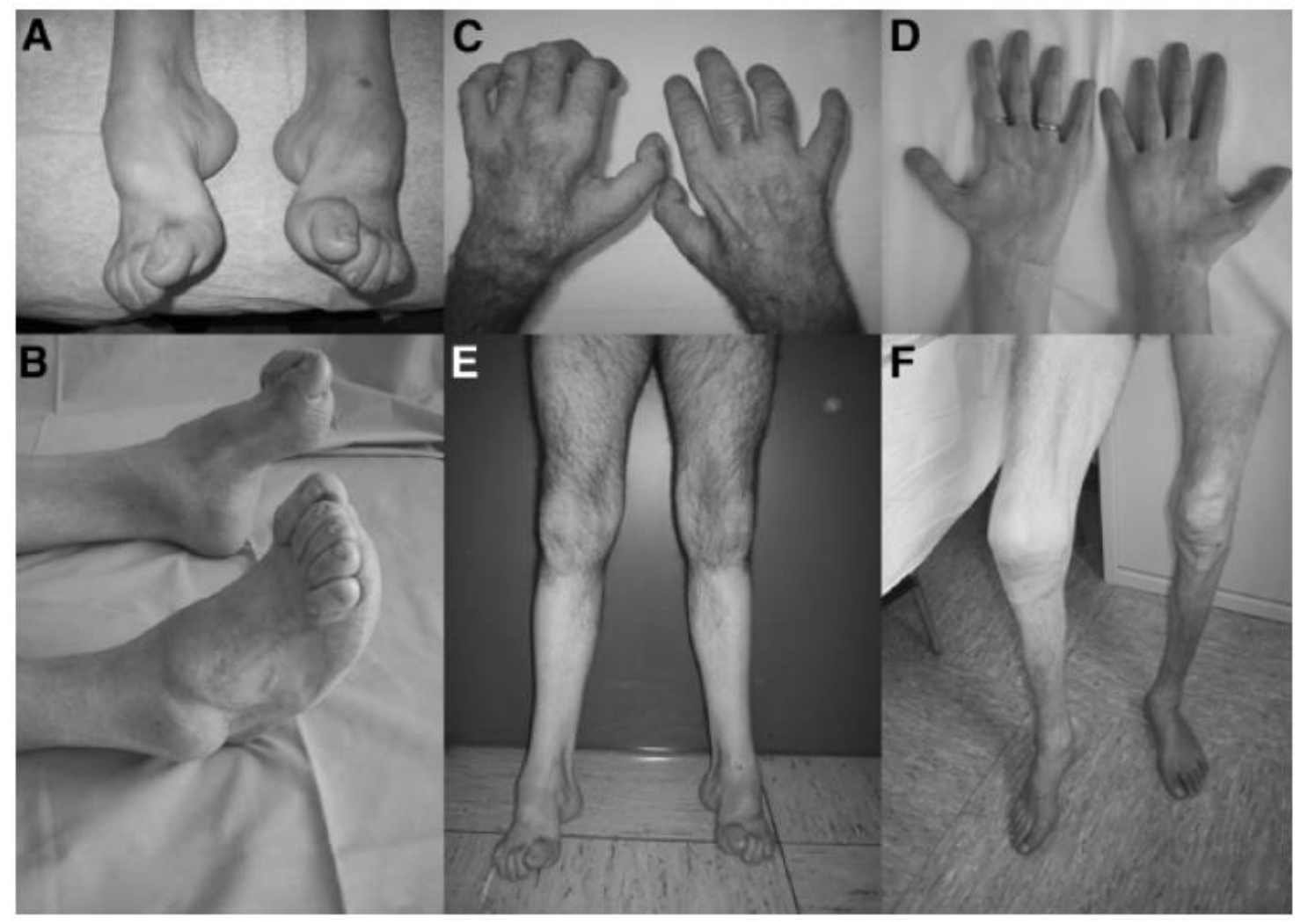

Abb. 1: Klinische Symptomatik der CMT

Klinische Symptomatik der CMT: mittlere bis schwere Fußdeformationen in Form des pes cavus, Geschwüren und Hammerzehen (A und B), Muskelatrophie im Bereich der Handmuskulatur ( $C$ und $D$ ), Muskelatrophie im Bereich des Unterschenkels ( $E$ und $F$ ). (Pareyson und Marchesi 2009; die Verwendung erfolgt mit freundlicher Genehmigung des Elsevier-Verlags) 


\subsection{Die Therapie der CMT}

Die CMT gehört zur Gruppe der Polyneuropathien, einer Gruppe, welche eine Vielzahl von Erkrankungen des peripheren Nervensystems umfasst, deren Gemeinsamkeit eine Schädigung mehrerer peripherer Nerven ist. Zu den typischen Ursachen von Polyneuropathien zählen neben internistischen Erkrankungen wie Diabetes mellitus, Alkoholabusus und Infektionen auch autoimmunologische Erkrankungen (z. B. Guillain-Barré-Syndrom), Medikamente (z. B. Oxaliplatin), die Exposition gegenüber industriellen Toxinen (z. B. Schwermetalle) oder neurogenetische Erkrankungen (z. B. CMT).

Neben einer Vielzahl von Ursachen, die einer Polyneuropathie zugrunde liegen können, ist die Ätiologie und Pathogenese eines großen Teils der Polyneuropathien nicht vollständig geklärt oder sogar weitestgehend unbekannt. Demzufolge liefern die derzeit verfügbaren Therapieansätze im Falle einer Vielzahl von Polyneuropathien nur unbefriedigende Ergebnisse.

Eine kausale Therapie ist vor allem für die neurogenetisch bedingten Polyneuropathien, zu denen auch die CMT zählt, oftmals nicht bekannt. Zur Linderung der Symptome werden im Rahmen der Therapie der CMT physiotherapeutische, orthopädietechnische und chirurgische Verfahren angewandt. Der positive Einfluss dieser Therapieansätze auf die Symptomatik und die klinischen Parameter der betroffenen Patienten ist jedoch limitiert und die Therapieerfolge verbleiben somit verbesserungsbedürttig.

Nach derzeitigem Stand der Technik ist keine medikamentöse Therapie für die CMT bekannt. Eine solche pharmakologische Therapiestrategie, die die pathomechanischen Grundlagen der CMT berücksichtigen könnte, käme einem kausalen Ansatz wesentlich näher als die bisher bekannten Therapieansätze. Infolgedessen wäre die Aussicht auf erhöhte Therapieerfolge im Rahmen pharmakologischer Therapiestrategien verbessert, weswegen ihre Entwicklung ein Gegenstand der aktuellen medizinischen Forschung verbleibt. 


\subsection{Experimentelle pharmakologische Therapiestrategien für die CMT}

Neben therapeutischen Ansätzen, die lediglich auf die Linderung der Beschwerden mittels Physiotherapie, Orthopädietechnik und Chirurgie abzielen, ist keine medikamentöse Therapie für die Behandlung der CMT und vieler anderer Polyneuropathien verfügbar. Aus diesem Grund verbleibt die Entwicklung pharmakologischer Therapiestrategien zur Behandlung der CMT weiterhin Gegenstand der aktuellen medizinischen Forschung.

Die Grundlage dieser Forschung sind Tiermodelle, die im Falle der Imitation der CMT1A Pmp22 transgen sind. Hierzu zählen neben einem Mausmodell (Huxley et al. 1996) auch ein Rattenmodell, die CMT-Ratte (Sereda et al. 1996). Vor allem die CMT-Ratte ahmt die humane CMT1A sowohl auf histopathologischer, neurophysiologischer als auch phänotypischer Ebene besonders suffizient nach (Sereda et al. 1996). Neben den Tiermodellen für die CMT1A existieren weiterhin Mausmodelle für die CMT1X und die CMT1B (Klein et al. 2014), ein Modell im Zebrafisch für die CMT2A (Chapman et al. 2013) sowie ein Modell in der Fruchtfliege (Drosophila melanogaster) für die CMT2B (Janssens et al. 2014).

$\mathrm{Zu}$ den experimentell untersuchten pharmakologischen Therapiestrategien zur Behandlung der CMT zählen die Verabreichung von Ascorbinsäure (Passage et al. 2004), eines Progesteronantagonisten (Sereda et al. 2003), von Curcumin (Khajavi et al. 2007), von Neurotrophin-3 (Sahenk et al. 2005), von Neuregulin-1 (Fledrich et al. 2014), von Rapamycin (Nicks et al. 2014), von HDAC6-Inhibitoren (d'Ydewalle et al. 2011) und von PXT-3003 (Kombination von Baclofen, Naltrexone und Sorbitol) (Chumakov et al. 2014) welche an unterschiedlichen Tiermodellen erprobt wurden. Zwei der vorgenannten Substanzen, Ascorbinsäure und PXT-3003 wurden ebenfalls in klinischen Studien erprobt. Mit Ascorbinsäure konnte jedoch kein Therapieerfolg bei CMT1A Patienten nachgewiesen werden. Lediglich PXT-3003, welches die Phase 2 der klinischen Studien durchlaufen hat, war in der Lage den Charcot-Marie-Tooth neuropathy 
score (CMTNS) und den Overall Neuropathy Limitations Scale (ONLS) von CMT1A-Patienten mäßig zu verbessern (Attarian et al. 2014). In Anbetracht der lediglich partiellen Erfolge im Bereich der Entwicklung pharmakologischer Therapiestrategien für die CMT verbleibt die Forschung auf diesem Gebiet somit von herausragender Relevanz.

\subsection{Experimentelle Therapiestudien mit phospholipidreicher Ernährung und Zielsetzung des Promotionsvorhabens}

Den experimentellen Therapiestudien, welche in dieser Arbeit geschildert werden, ging die Beobachtung voraus, dass bereits geringe Mengen von Phospholipiden, sofern sie der CMT-Ratte mit der Nahrung verabreicht werden, einen positiven Einfluss auf die klinische Symptomatik der Versuchstiere haben. So konnte in dieser nicht veröffentlichten Arbeit gezeigt werden, dass bereits ein 0,03 \%iger Zusatz von L- $\alpha$-Phosphatidylcholin zu einer Verbesserung klinischer Erkrankungsparameter führt.

Basierend auf den vorgenannten Beobachtungen verfolgt die hier vorgelegte Arbeit die Zielsetzung das Potenzial einer phosplipidreichen Ernährung hinsichtlich der therapeutischen Beeinflussung von Erkrankungsparametern der CMT1A zu analysieren. Im Rahmen von insgesamt drei experimentellen Therapiestudien an der CMT-Ratte wurden die klinische Symptomatik sowie elektrophysiologische und histopathologische Paramater untersucht. Um den therapeutischen Effekt auf die Erkrankungsparameter der CMT1A möglichst detailliert analysieren zu können, unterscheiden sich die nachfolgend beschriebenen experimentellen Therapiestudien hinsichtlich der Verabreichungszeitpunkte, der Therapiedauer und der eingesetzten Wirkstoffmenge. 


\section{Material und Methoden}

\subsection{Material}

\subsubsection{Verbrauchsmaterialien}

Tab. 1: Verbrauchsmaterialien

\begin{tabular}{|l|l|}
\hline Material & Hersteller \\
\hline $\mathrm{CO}_{2}$-Gas & Messer Group GmbH \\
\hline Deckgläschen & Thermo Fischer Scientific \\
\hline $\begin{array}{l}\text { Einmal-Untersuchungshandschuhe „Peha- } \\
\text { soft® powderfree“ }\end{array}$ & Paul Hartmann AG \\
\hline Eppendorf Tubes ${ }^{\circledR}$ & Eppendorf AG \\
\hline Falcon ${ }^{\text {MM }}$ Tubes, verschiedene Größen & BD Biosciences \\
\hline $\begin{array}{l}\text { Injektionskanülen „BD Microlance } \\
\text { tM“, }\end{array}$ & BD Biosciences \\
\hline Objektträger & Thermo Fischer Scientific \\
\hline $\begin{array}{l}\text { PCR-Mikrotiterplatten „SuperPlate 96-Well } \\
\text { PCR Plate“ }\end{array}$ & Thermo Fischer Scientific \\
\hline PCR-Plattenfolie „AirPore Tape Sheets“ & Qiagen N.V. \\
\hline Pipettenspitzen & Thermo Fischer Scientific \\
\hline Rattenstandarddiät ssniff R/Z V1325-0 & ssniff Spezialdiäten GmbH \\
\hline HSW NORM-JECT ${ }^{\circledR}$ - Einmalspritzen & Henke-Sass, Wolf GmbH \\
\hline Transferpipetten & Bio-Rad Laboratories, Inc. \\
\hline Trockeneis & Messer Group GmbH \\
\hline Weichholzgranulateinstreu „Bedding S8/15“ & ssniff Spezialdiäten GmbH \\
\hline
\end{tabular}

\subsubsection{Chemikalien}

Tab. 2: Chemikalien

\begin{tabular}{|l|l|}
\hline Chemikalie & Hersteller \\
\hline Methylnadicanhydrid (MNA) & $\begin{array}{l}\text { SERVA Electrophoresis } \\
\text { GmbH }\end{array}$ \\
\hline $\begin{array}{l}\text { 2,4,6-Tris(dimethylaminomethyl)phenol } \\
\text { (DMP30) }\end{array}$ & $\begin{array}{l}\text { SERVA Electrophoresis } \\
\text { GmbH }\end{array}$ \\
\hline 2-Duodecenyl-succinicacidanhydrid (DDSA) & $\begin{array}{l}\text { SERVA Electrophoresis } \\
\text { GmbH }\end{array}$ \\
\hline Agarose & Bio-Rad Laboratories, Inc. \\
\hline Azur-II-Farbstoff & Merck KGaA \\
\hline $\begin{array}{l}\text { Dinatriumhydrogenphosphat-Dihydrat } \\
\left(\text { Na }_{2} \mathrm{HPO}_{4} \times 2 \mathrm{H}_{2} \mathrm{O}\right)\end{array}$ & Merck KGaA \\
\hline Ethidiumbromid & Sigma-Aldrich \\
\hline EUKITT® & O. Kindler GmbH \\
\hline Glutardialdehyd & Merck KGaA \\
\hline
\end{tabular}




\begin{tabular}{|l|l|}
\hline Chemikalie & Hersteller \\
\hline Glycidether & $\begin{array}{l}\text { SERVA Electrophoresis } \\
\text { GmbH }\end{array}$ \\
\hline Kaliumchlorid $(\mathrm{KCl})$ & Merck KGaA \\
\hline Kaliumdihydrogenphosphat & Merck KGaA \\
\hline Methanol & Merck KGaA \\
\hline Methylenblau & Merck KGaA \\
\hline Natriumchlorid $(\mathrm{NaCl})$ & Merck KGaA \\
\hline $\begin{array}{l}\text { Natriumdihydrogenphosphat-Monohydrat } \\
\left(\mathrm{NaH}_{2} \mathrm{PO}_{4} \times \mathrm{H}_{2} \mathrm{O}\right)\end{array}$ & Merck KGaA \\
\hline $\mathrm{Natriumhydroxid}(\mathrm{NaOH})^{\text {Osmiumtetroxid }}$ & Merck KGaA \\
& $\begin{array}{l}\text { SERVA Electrophoresis } \\
\text { GmbH }\end{array}$ \\
\hline Paraformaldehyd (PFA) & $\begin{array}{l}\text { SERVA Electrophoresis } \\
\text { GmbH }\end{array}$ \\
\hline Salzsäure (HCl) & $\begin{array}{l}\text { SERVA Electrophoresis } \\
\text { GmbH }\end{array}$ \\
\hline
\end{tabular}

\subsubsection{Pharmakologische Substanzen}

Tab. 3: Pharmakologische Substanzen

\begin{tabular}{|l|l|}
\hline Pharmakon & Hersteller \\
\hline Ketamin (Ketanest®) & Parke-Davis \\
\hline $\begin{array}{l}\text { L-a-Phosphatidylcholin aus Sojabohnen, Typ IV-S, } \geq \\
30 \% \text { (enzymatisch) }\end{array}$ & Sigma-Aldrich \\
\hline Natriumcholridlösung $0,9 \%$ & $\begin{array}{l}\text { Diaco } \\
\text { Biofarmaceutici S.r.I. }\end{array}$ \\
\hline Xylazin (Rompun®) & Bayer AG \\
\hline
\end{tabular}

\subsubsection{Ergänzende Angaben zu L- $\alpha-P h o s p h a t i d y l c h o l i n$ aus Sojabohnen,} Typ IV-S, $\geq 30$ \% (enzymatisch)

Das für die Behandlung der CMT-Ratte verwendete und unter der Bezeichnung "L- $\alpha$-Phosphatidylcholine from soybean, Type IV-S, $\geq 30 \%$ (enzymatic)" vertriebene und in dieser Arbeit als Futterzusatz verwendete Substanzgemisch enthält laut Herstellerangaben neben durchschnittlich $55 \%$ Phosphatidylcholinen einen Anteil von durchschnittlich $20 \%$ Phosphatidylethanolaminen sowie einen nicht näher quantifizierten Anteil an Spuren von Kohlenhydraten und Lipiden. 
Gemäß den Herstellerangaben finden sich die Reste folgender Fettsäuren in dem Substanzgemisch: $17 \%$ Palmitinsäure (C16:0), 4 \% Stearinsäure (C18:0), 9 \% Ölsäure (C18:1), 60 \% Linolsäure (C18:2), 7 \% Linolensäure (C18:3).

\subsubsection{Lösungen und Puffer}

\subsubsection{Phosphatgepuffertes Glutaraldehyd zur Fixierung von Präparaten} für die Lichtmikroskopie (Karlsson und Schultz 1965)

Tab. 4: Zusammensetzung von phosphatgepuffertem Glutaraldehyd

\begin{tabular}{|l|l|}
\hline Substanz & Masse/ Volumen \\
\hline Natriumhydrogenphosphat $\times \mathrm{H}_{2} \mathrm{O}$ & $0,36 \mathrm{~g}$ \\
\hline Dinatriumhydrogenphosphat $\times 2 \mathrm{H}_{2} \mathrm{O}$ & $3,1 \mathrm{~g}$ \\
\hline Natriumcholrid & $1 \mathrm{~g}$ \\
\hline Glutardialdehydlösung & $20 \mathrm{ml}$ \\
\hline Paraformaldehyd & $8 \mathrm{~g}$ \\
\hline
\end{tabular}

Das in $60 \mathrm{ml} \mathrm{ddH_{2 }} \mathrm{O}$ gelöste PFA-Pulver wird unter ständigem Rühren auf eine Temperatur von $60-70{ }^{\circ} \mathrm{C}$ und anschließend mit $\mathrm{ddH}_{2} \mathrm{O}$ auf ein Gesamtvolumen von $80 \mathrm{ml}$ aufgefüllt. Es folgt eine tröpfchenweise Zugabe von $1 \mathrm{M}$ $\mathrm{NaOH}$ bis zum Aufklaren der Lösung, die nun steril filtriert und mithilfe von $1 \mathrm{M}$ $\mathrm{HCl}$ auf einen $\mathrm{pH}-$ Wert von 7,4 eingestellt wird. Nun werden die o. g. Salze in

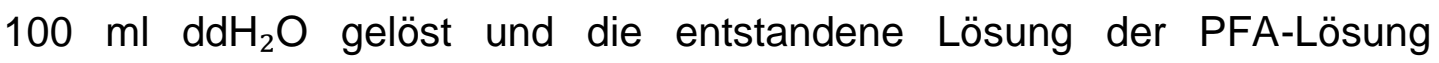
zugegeben. Letztlich wird die Lösung mit Glutardialdehyd versetzt.

\subsubsection{Gebrauchslösung zur Narkose}

Tab. 5: Zusammensetzung der Gebrauchslösung zur Narkose

\begin{tabular}{|l|l|}
\hline Substanz & Volumen \\
\hline Ketamin $(10 \%)$ & $0,75 \mathrm{ml}$ \\
\hline Xylazin $(2 \%)$ & $0,2 \mathrm{ml}$ \\
\hline $\mathrm{NaCl}(0,9 \%)$ & $9,05 \mathrm{ml}$ \\
\hline
\end{tabular}

Die o. g. Pharmaka werden zu einer Gebrauchslösung für die Injektionsnarkose der Versuchstiere gemischt. 


\subsubsection{Aliphatisches Epoxidharz „Epon“ zur Einbettung histologischer} Präparate (Luft 1961)

Vorerst wird die Eponlösung A mit folgenden Substanzen hergestellt:

Tab. 6: Zusammensetzung der Eponlösung A

\begin{tabular}{|l|l|}
\hline Substanz & Masse \\
\hline Glycidether & $67,5 \mathrm{~g}$ \\
\hline DDSA & $88,2 \mathrm{~g}$ \\
\hline
\end{tabular}

Die so entstandene Lösung wird eine Stunde lang im Magnetrührer gerührt.

Nun wird die Eponlösung B mit folgenden Substanzen hergestellt:

Tab. 7: Zusammensetzung der Eponlösung B

\begin{tabular}{|l|l|}
\hline Substanz & Masse \\
\hline Glycidether & $82,3 \mathrm{~g}$ \\
\hline MNA & $73,3 \mathrm{~g}$ \\
\hline
\end{tabular}

Die so entstandene Lösung wird eine Stunde lang im Magnetrührer gerührt. Die Eponlösungen $A$ und $B$ werden nun im Verhältnis von 1:1 miteinander vermischt und unter Zugabe von 1,8 \% DMP30 entsteht so die Epongebrauchslösung.

\subsubsection{Schnellfärbelösung „Methylen-Azur II“ für histologische} Präparate (Richardson et al. 1960)

Vorerst wird zur Herstellung der Methylenblau-Lösung $1 \%$ Methylenblau mit 1 \% Boraxlösung gemischt. Die Azur-II-Lösung wird aus 1 \% Azur II gelöst in $\mathrm{H}_{2} \mathrm{O}$ hergestellt. Eine Mischung der beiden vorgenannten Lösungen im Verhältnis von 1:1 ergibt die Methylen-Azur-II-Färbelösung.

\subsubsection{4 \%ige PFA-Lösung in phosphatgepufferter Salzlösung (PBS)}

Es werden $40 \mathrm{~g}$ PFA-Pulver in $500 \mathrm{ml} \mathrm{H}_{2} \mathrm{O}$ gelöst und für 15 Minuten auf $60^{\circ} \mathrm{C}$ erhitzt. Daraufhin erfolgt die tröpfchenweise Zugabe von $1 \mathrm{M} \mathrm{NaOH}$ bis die Lösung aufklart, woraufhin sie steril filtriert und schließlich auf einen $\mathrm{pH}$-Wert von 7,4 eingestellt wird. Letztlich werden der Lösung $500 \mathrm{ml}$ eines $0,2 \mathrm{M}$ Phosphatpuffers zugesetzt. 


\subsubsection{PBS (10-fach)}

Tab. 8: Zusammensetzung von PBS (10-fach)

\begin{tabular}{|l|l|}
\hline Substanz & Masse \\
\hline $\mathrm{NaCl}$ & $100 \mathrm{~g}$ \\
\hline $\mathrm{KCl}$ & $2,5 \mathrm{~g}$ \\
\hline $\mathrm{Na}_{2} \mathrm{HPO}_{4} \times \mathrm{H}_{2} \mathrm{O}$ & $7,2 \mathrm{~g}$ \\
\hline $\mathrm{KH}_{2} \mathrm{PO}_{4} \times 2 \mathrm{H}_{2} \mathrm{O}$ & $2,5 \mathrm{~g}$ \\
\hline
\end{tabular}

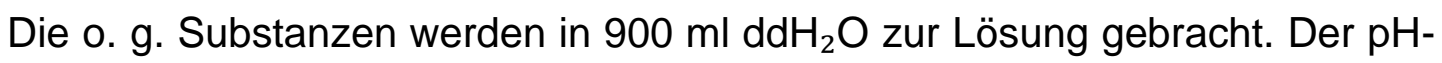
Wert dieser Lösung wird anschließend durch die Zugabe von $1 \mathrm{M} \mathrm{NaOH}$ auf 7,2 eingestellt und das Volumen der Lösung mit dd $\mathrm{H}_{2} \mathrm{O}$ auf $1000 \mathrm{ml}$ aufgefüllt. Letztlich wird die Lösung autoklaviert und kann nach einer 1:10 Verdünnung verwendet werden.

\subsubsection{Puffer des „DNeasy 96 Kits“}

Der Hersteller macht keine näheren Angaben zur Zusammensetzung der Puffer.

\subsubsection{TRIS-Acetat-EDTA-Puffer (TAE-Puffer) (50-fach)}

Tab. 9: Zusammensetzung des TAE-Puffers

\begin{tabular}{|l|l|}
\hline Substanz & Masse/ Volumen \\
\hline TRIS-HCl Base & $242 \mathrm{~g}$ \\
\hline Essigsäure 100 \% & $57,1 \mathrm{ml}$ \\
\hline EDTA $(0,5 \mathrm{M}, \mathrm{pH} 8)$ & $100 \mathrm{ml}$ \\
\hline
\end{tabular}

Die Mischung der o. g. Substanzen wird mit dd $\mathrm{H}_{2} \mathrm{O}$ auf $1000 \mathrm{ml}$ aufgefüllt.

\subsubsection{Enzyme und Reaktionskomplettsysteme}

Tab. 10: Enzyme und Reaktionskomplettsysteme

\begin{tabular}{|l|l|}
\hline Bezeichnung & Hersteller \\
\hline DNeasy 96 Kit für DNA Isolation & Qiagen N.V. \\
\hline Proteinkinase K & $\begin{array}{l}\text { Boehringer Ingelheim GmbH und Co. } \\
\text { KG }\end{array}$ \\
\hline Taq-DNA-Polymerase $(5 \mathrm{U} / \mu \mathrm{l})$ & $\begin{array}{l}\text { Boehringer Ingelheim GmbH und Co. } \\
\text { KG }\end{array}$ \\
\hline
\end{tabular}




\subsubsection{Nukleinsäuren}

Tab. 11: Nukleinsäuren

\begin{tabular}{|l|l|}
\hline Bezeichnung & Hersteller \\
\hline $\begin{array}{l}\text { Desoxyribonukleosidtriphosphat } \\
\text { (dNTP) }\end{array}$ & $\begin{array}{l}\text { Boehringer Ingelheim GmbH und Co. } \\
\text { KG }\end{array}$ \\
\hline $\begin{array}{l}\text { DNA-Größenmarker „PhiX174/ } \\
\text { HaellI“ }\end{array}$ & Promega Corporation \\
\hline
\end{tabular}

\subsubsection{Oligonukleotide}

$\begin{array}{ll}\text { PMP22 tg (Rattus) } & \begin{array}{l}\text { sense primer } \\ \text { antisense primer }\end{array}\end{array}$ 5'-CCAGAAAGCCAGGGAACTC-3' 5'-GACAAACCCCAGACAGTTG-3'

\subsubsection{Geräte}

Tab. 12: Geräte

\begin{tabular}{|l|l|}
\hline Gerät & Hersteller \\
\hline $\begin{array}{l}\text { Gelkammer mit Kämmen für die } \\
\text { wgarosegelelektrophorese }\end{array}$ & $\begin{array}{l}\text { wissenschaftliche Werkstatt des } \\
\text { MPI Ër Experimentelle Medizin }\end{array}$ \\
\hline Zentrifuge „Centrifuge 5403“ & Eppendorf AG \\
\hline $\begin{array}{l}\text { Elektrophysiologiegerät } \\
\text { „Neuroscreen“ }\end{array}$ & Jaeger Tönnies GmbH \\
\hline Gefrierschrank (bis -20 ${ }^{\circ} \mathrm{C}$ ) & Liebherr-International AG \\
\hline $\begin{array}{l}\text { Gefrierschrank (bis }-85^{\circ} \mathrm{C} \text { ) „Ultra } \\
\text { Low Freezer“ }\end{array}$ & New Brunswick Scientific Co., Inc. \\
\hline Newtonmeter „Typ 708“ & ERICHSEN Wuppertal \\
\hline Präparationsbesteck & Fine Science Tools GmbH \\
\hline $\begin{array}{l}\text { Reinstwasseranlage „Arium 611 } \\
\text { VF“ }\end{array}$ & Sartorius AG \\
\hline $\begin{array}{l}\text { Rotationsmikrotom „Reichert } \\
\text { Ultracut S“ }\end{array}$ & Leica Microsystems AG \\
\hline $\begin{array}{l}\text { EPS-301 ELECTROPHORESIS } \\
\text { POWER SUPPLY }\end{array}$ & $\begin{array}{l}\text { Amersham Pharmacia Biotech } \\
\text { (heute GE Healthcare) }\end{array}$ \\
\hline Proben-Trimmer „EM TRIM“ & Leica Microsystems AG \\
\hline UV-Illuminator & $\begin{array}{l}\text { Amersham Pharmacia Biotech } \\
\text { (heute GE Healthcare) }\end{array}$ \\
\hline Zentrifuge „4K15C“ & SIGMA Laborzentrifugen GmbH \\
\hline
\end{tabular}




\subsubsection{Software}

Tab. 13: Software

\begin{tabular}{|c|c|}
\hline Software & Hersteller \\
\hline $\begin{array}{l}\text { Excel® für Mac, } \\
\text { Version } 15.24\end{array}$ & Microsoft Europe \\
\hline Fotos, Version 1.5 & Apple Inc. \\
\hline $\begin{array}{l}\text { Adobe } \AA \text { Illustrator } \\
\text { CS5, Version } 15.0 .2\end{array}$ & Adobe Systems Software Ireland Ltd. \\
\hline ImageJ, Version 1.46r & National Institutes of Health $(\mathrm{NIH})$ \\
\hline $\begin{array}{l}\text { Adobe® Photoshop } \AA \\
\text { CS5, Version 12.0.4 }\end{array}$ & Adobe Systems Software Ireland Ltd. \\
\hline PyRAT & Scionics Computer Innovation GmbH \\
\hline Pages, Version 5.6.2 & Apple Inc. \\
\hline $\begin{array}{l}\text { IBM® SPSS } \AA \\
\text { Statistics, Version } \\
24.0 .0 .0\end{array}$ & IBM Corporation \\
\hline $\begin{array}{l}\text { Word® für Mac, } \\
\text { Version 15.24 }\end{array}$ & Microsoft Europe \\
\hline
\end{tabular}

\subsubsection{Die CMT-Ratte}

Zur Untersuchung der Auswirkungen einer phospholipidreichen Ernährung wurde der CMT-Ratte, einem Tiermodell für die CMT1A Erkrankung, mit L- $\alpha$ Phosphatidylcholin angereichertes Futter verabreicht.

Die CMT-Ratte ist ein PMP22-transgenes Tiermodell, welches drei zusätzliche Kopien des murinen Genes für das PMP22 in der Chromosomenregion 17p11.2-12 trägt und die humane CMT1A sowohl auf histopathologischer, neurophysiologischer als auch phänotypischer Ebene besonders suffizient nachahmt (Sereda et al. 1996).

Auf histopathologischer Ebene kann bei der CMT-Ratte eine signifikant verringerte Anzahl an Axonen im Nervus tibialis sowie eine signifikante Hypomyelinisierung) der Axone des Nervus ischiadicus beobachtet werden (Meyer zu Hörste et al. 2007).

Auf neurophysiologischer Ebene kann bei der CMT-Ratte eine signifikant verringerte NLG, signifikant reduzierte CMAP, signifikant reduzierte sensible 
Nervenaktionspotentiale (SNAP) sowie eine signifikant reduzierte sensible Nervenleitgeschwindigkeit (SNCV) beobachtet werden (Sereda et al. 1996). Auf phänotypischer Ebene ist vor allem der Griffstärketest, welcher bei der CMT-Ratte insbesondere an deren Hinterläufen signifikant reduzierte Werte hervorbringt, erwähnenswert (Meyer zu Hörste et al. 2007).

\subsection{Methoden}

\subsubsection{Studiendesign und Tierauswahl}

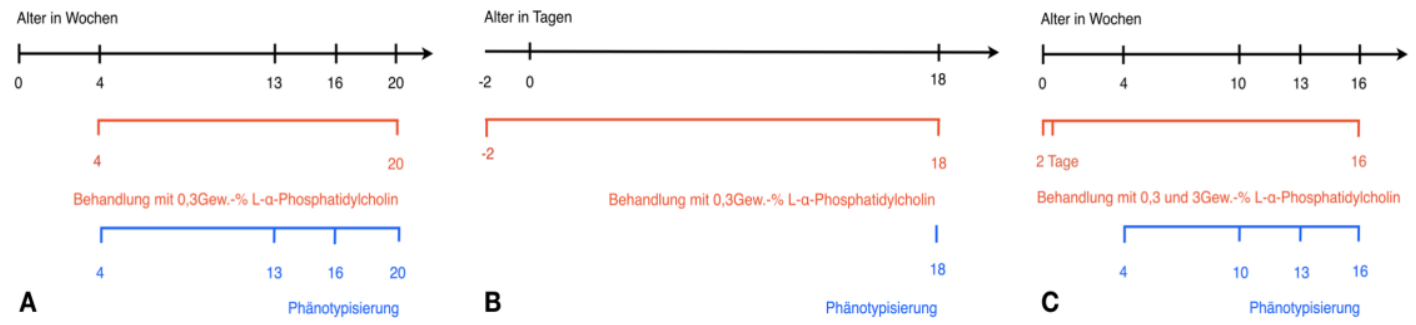

Abb. 2: Zeitlicher Ablauf der verschiedenen Therapiestudien

Die drei nachfolgend geschilderten Therapiestudien wurden an Ratten der Linie Sprague-Dawley durchgeführt. Für die Studien mit spätem (A) und frühem (C) Behandlungsbeginn wurden ausschließlich männliche Tiere beider Genotypen, Wildtyp und CMT-Ratte, verwendet. Für Kurzzeitstudie mit frühem Behandlungsbeginn (B) wurden beide Geschlechter ebenfalls beider Genotypen verwendet, da geschlechtsspezifische Unterschiede zwischen den Versuchstieren aufgrund des geringen Lebensalters bei Studienende zu vernachlässigen waren und diese Studie lediglich einen ungefähren Trend für das weitere Vorgehen liefern sollte.

Die Zucht und Haltung aller Versuchstiere erfolgte innerhalb des Tierhauses des MPI für Experimentelle Medizin. Die durchgeführten genehmigungspflichtigen Tierversuche wurden vom Niedersächsischen 
Landesamt für Verbraucherschutz und Lebensmittelsicherheit (LAVES) unter der Nummer 33.9-42502-04-12/0837 genehmigt.

Innerhalb der Studie mit spätem Behandlungsbeginn wurden die CMT-Ratte und entsprechende Kontrolltiere als Versuchstiere ab dem 28. Postnataltag bis zur 20. Lebenswoche behandelt.

Innerhalb der Kurzzeitstudie mit frühem Behandlungsbeginn wurden die CMTRatte und entsprechende Kontrolltiere als Versuchstiere ab dem 21. Embryonaltag bis zum 18. Postnataltag behandelt.

Innerhalb der Studie mit frühem Behandlungsbeginn wurden die CMT-Ratte und entsprechende Kontrolltiere als Versuchstiere ab dem zweiten Postnataltag bis zur 16. Lebenswoche behandelt.

Das Studiendesign beinhaltete eine randomisierte Auswahl der Versuchstiere, wobei die Versuchsgruppen der Studien mit spätem und frühem Behandlungsbeginn hinsichtlich ihrer Gruppengröße gemäß dem Stand der Technik (Meyer zu Hörste et al. 2007) festgesetzt wurden. Die Gruppengrößen der Kurzzeitstudie konnten erst im Anschluss an die Studie ermittelt werden, da eine Genotypisierung der Versuchstiere erst zu diesem Zeitpunkt durchgeführt wurde.

Die Versuchstiere der Studie mit spätem Behandlungsbeginn wurden in vier Gruppen eingeteilt, wobei zwei dieser Gruppen ausschließlich Wildtyp-Ratten und die anderen zwei Gruppen ausschließlich CMT-Ratten beinhalteten. In den zwei Gruppen mit ausschließlich Wildtyp-Ratten erhielt die erste Gruppe die Rattenstandarddiät ohne Zusatz und die zweite Gruppe die Rattenstandarddiät mit einem Zusatz von 0,3 Gew.-\% L-a-Phosphatidylcholin. In den zwei Gruppen mit ausschließlich CMT-Ratten erhielt die erste Gruppe die Rattenstandarddiät ohne Zusatz und die zweite Gruppe die Rattenstandarddiät mit einem Zusatz von 0,3 Gew.-\% L-a-Phosphatidylcholin. Bei den Versuchstieren der Kurzzeitstudie ergaben sich vier Gruppen aufgrund der Tatsache, dass ein Teil der Muttertiere die Rattenstandarddiät ohne Zusatz und der andere Teil die Rattenstandarddiät mit einem Zusatz von 
0,3 Gew.-\% L-a-Phosphatidylcholin erhielt. Da alle Muttertiere Jungtiere beider Genotypen hervorbrachten ergaben sich zwei Gruppen mit ausschließlich Wildtyp-Ratten von denen die erste Gruppe keine erhöhte Dosis an L- $\alpha$-Phosphatidylcholin (Rattenstandarddiät ohne Zusatz) und die zweite Gruppe eine erhöhte Dosis an L-a-Phosphatidylcholin (Rattenstandarddiät mit einem Zusatz von 0,3 Gew.-\%) über die Muttermilch erhielt. In den zwei Gruppen mit ausschließlich CMT-Ratten erhielt die erste Gruppe ebenso keine erhöhte Dosis an L-a-Phosphatidylcholin (Rattenstandarddiät ohne Zusatz) und die zweite Gruppe eine erhöhte Dosis an L-a-Phosphatidylcholin (Rattenstandarddiät mit einem Zusatz von 0,3 Gew.-\%) über die Muttermilch.

Die Versuchstiere der Studie mit frühem Behandlungsbeginn wurden in sechs Gruppen eingeteilt, wobei drei dieser Gruppen ausschließlich Wildtyp-Ratten und die anderen drei Gruppen ausschließlich CMT-Ratten beinhalteten. In den drei Gruppen mit ausschließlich Wildtyp-Ratten erhielt die erste Gruppe die Rattenstandarddiät ohne Zusatz, die zweite Gruppe die Rattenstandarddiät mit einem Zusatz von 0,3 Gew.-\% L-a-Phosphatidylcholin und die dritte Gruppe die Rattenstandarddiät mit einem Zusatz von 3,0 Gew.-\% L-aPhosphatidylcholin. In den drei Gruppen mit ausschließlich CMT-Ratten erhielt die erste Gruppe die Rattenstandarddiät ohne Zusatz, die zweite Gruppe die Rattenstandarddiät mit einem Zusatz von 0,3 Gew.-\% L-a-Phosphatidylcholin und die dritte Gruppe die Rattenstandarddiät mit einem Zusatz von 3,0 Gew.$\%$ L-a-Phosphatidylcholin.

Die Wildtyp-Ratten, welche das Futtermittel für Ratten mit unterschiedlichen Anteilen an zugesetztem L- $\alpha$-Phosphatidylcholin erhielten, wurden als Positivkontrollen in allen der o. g. Studien geführt. 


\subsubsection{Verhaltenstests und phänotypische Untersuchungen}

\subsubsection{Griffstärke}

Die Versuchstiere der Studien mit frühem und spätem Behandlungsbeginn wurden in jeder dritten bis vierten Woche einer Messung der Griffstärke an Vorder- und Hinterläufen unterzogen. Bei den Versuchstieren der Kurzzeitstudie mit frühem Behandlungsbeginn erfolgten diese Messungen am letzten Tag der Studie, dem 18. Postnataltag. Für Vorder- und Hinterläufe wurden je fünf Messungen durchgeführt, wobei der Mittelwert dieser fünf Messungen dem jeweiligen Tier zugeordnet wurde. Jede Messung der Griffstärke wurde von demselben, für alle Experimente geblindeten Untersucher, zur gleichen Tageszeit und innerhalb derselben Räumlichkeit durchgeführt um ein größtmögliches Ausmaß an Vergleichbarkeit der Ergebnisse zu erzielen.
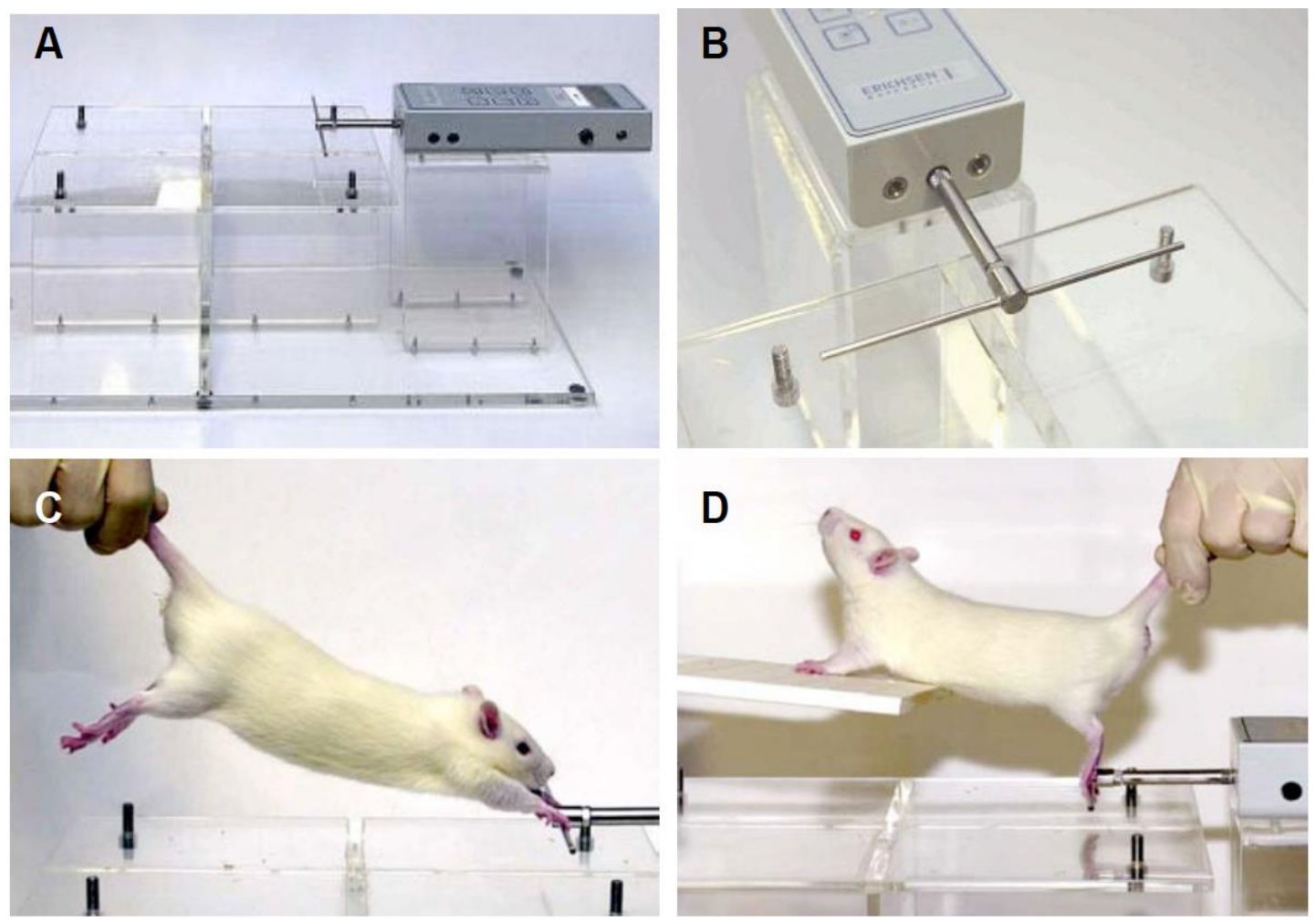

Abb. 3: Messung der Griffstärke an Vorder- und Hinterläufen (mit freundlicher Genehmigung von Dr. med. Thomas Prukop) 
Die Messung der Griffstärke erfolgte indem das Versuchstier, welches die Haltestange des O. g. Newtonmeters (A und B) entweder mit seinen Vorderoder seinen Hinterläufen griff, vom Untersucher am Schwanz gezogen wurde (C und D), wobei es zu einer Auslenkung der Haltestange kam. Die maximale Kraft, die das Versuchstier hierbei beim Loslassen der Haltestange aufbrachte, fand Eingang in den erhobenen Datensatz.

Neben unvermeidlichen Störgrößen mit sensorischer (z. B. krankheitsbedingte Schmerzen) und verhaltenstypischer (z. B. Motivation) Ausrichtung ist für das Erreichen dieser Maximalkraft hauptsächlich die Stärke der jeweils beteiligten Muskulatur ausschlaggebend. Dieser Messung kommt folglich eine besondere Bedeutung in Bezug auf die Beurteilung der krankheitsbedingten Muskelatrophie zu.

\subsubsection{Bewertung der allgemeinen Gesundheit}

Im Rahmen der Messung der Griffstärke wurde zu jedem Zeitpunkt ebenfalls das Körpergewicht der Versuchstiere sowie ihr äußerliches Erscheinungsbild (Fell, Körperhaltung, Gang, usw.) im gesamten Verlauf der experimentellen Therapiestudie untersucht. Hierbei auftretende Anomalien, die mit einer korrekten Durchführung der Test negativ interferieren würden, wurden vermerkt und die Datensätze der betroffenen Versuchstiere aus den Statistiken ausgeschlossen.

\subsubsection{Molekularbiologische Verfahren}

\subsubsection{Isolation genomischer DNA aus Gewebeproben}

Die Genotypisierung der Versuchstiere, also ihre Differenzierung gemäß des Genotyps (Wildtyp oder PMP22-transgen), wurde mithilfe von Schwanzbiopsien, welche am ersten Postnataltag unter leichter Narkose mit 
$\mathrm{CO}_{2}$-Gas entnommen wurden, durchgeführt. Zur Isolation der genomischen DNA aus den Gewebeproben wurde das „DNeasy 96 Kit“ verwendet. Im ersten Schritt wurden die Komponenten $180 \mu$ I Puffer ATL und $20 \mu$ I Proteinkinase K miteinander vermischt und bei 3000 rpm zentrifugiert. Dieser Mischung wurde die Gewebeprobe hinzugefügt und über Nacht bei $55^{\circ} \mathrm{C}$ inkubiert, wobei ein Verdau der Gewebeprobe infolge der katalytischen Eigenschaften der Proteinkinase K erfolgte. Im nächsten Schritt wurde das so entstandene Lysat mit $400 \mu \mathrm{l}$ von Puffer AL/E vermischt, die Lösung bei 3000 rpm kurz zentrifugiert und der sich ergebende Überstand in einem Volumen von maximal $900 \mu \mathrm{l}$ auf die Silicamembran innerhalb der Säulen des „DNeasy 96 Kit“ transferiert. Nachdem die Säulen mit dem "AirPore Tape Sheet" verschlossen wurden folgte ein fünfminütiger Zentrifugationsschritt bei 6000 rpm. Im Anschluss an diesen Schritt erfolgte die Zugabe von $500 \mu \mathrm{l}$ Puffer AW1 sowie eine erneute Zentrifugation diesmal für 5 Minuten bei $6000 \mathrm{rpm}$. Es folgte das gleiche Vorgehen nach Zugabe von $500 \mu$ Puffer AW2 in dessen Anschluss die Proben für 15 Minuten bei $70^{\circ} \mathrm{C}$ inkubiert wurden. Mithilfe von $200 \mu \mathrm{l}$ Puffer AE (erwärmt) und anschließend weiteren $100 \mu \mathrm{l}$ Puffer AE (erwärmt) erfolgte nun die Eluation der an die Silicamembran gebundenen DNA, wobei sich nach jeder Eluation eine fünfminütige Inkubation bei $60^{\circ} \mathrm{C}$ mit anschließender zweiminütiger Zentrifugation bei $6000 \mathrm{rpm}$ anschloß. Die auf diesem Wege isolierte DNA war nun für eine Lagerung bei $4{ }^{\circ} \mathrm{C}$ und anschließende Prozessierung mittels der PCR bereit.

\subsubsection{Amplifikation der isolierten DNA mittels der Polymeraseketten- reaktion (PCR)}

Um die isolierte DNA mittels Amplifikation für die Genotypisierung nutzbar zu machen, wurde sich der PCR (Mullis et al. 1986) bedient. 
Ausgangssubstanzen der PCR:

- Matrizen-DNA ( $1 \mu \mathrm{l})$ : entspricht der zu amplifizierenden DNA-Sequenz aus den o. g. Schwanzbiopsien

- Taq-Polymerase (0,3 $\mu$ l): die thermostabile DNA-Polymerase des Bakteriums Thermus aquaticus mit einem Temperaturoptimum bei $72^{\circ} \mathrm{C}$

- Sense primer $(1 \mu \mathrm{l})$ : einsträngige Oligonucleotide, welche zu dem 5'-Ende der sense-DNA-Stränge der Template-DNA komplementär sind und als Ausgangspunkt für die Taq-Polymerase fungieren

- Antisense primer $(1 \mu \mathrm{l})$ : einsträngige Oligonucleotide, welche zu dem 5'-Ende der antisense-DNA-Stränge der Template-DNA komplementär sind und als Ausgangspunkt für die Taq-Polymerase fungieren

- dNTP (5 $\mu$ l): Desoxynucleosidtriphosphate, welche als Substrat der TaqPolymerase dienen

- PCR-Puffer von Promega (5 $\mu \mathrm{l})$ : Ein Puffersystem, welches den pH-Wert der Reaktionslösung trotz ständig auftretender Temperaturschwankungen im Ablauf der PCR relativ konstant im Bereich des pH-Optimums der TaqPolymerase, stabilisieren soll

Der fertige Reaktionsansatz aus den o. g. Ausgangssubstanzen wurde nun einer automatisierten PCR in einem Thermocycler gemäß folgendem Schema unterzogen:

1. Initiale Denaturierung bei $95^{\circ} \mathrm{C}$

3 Minuten

2. Annealing bei $56^{\circ} \mathrm{C}$

30 Sekunden

3. Elongation bei $72{ }^{\circ} \mathrm{C}$

90 Sekunden

4. Denaturierung bei $95^{\circ} \mathrm{C}$

60 Sekunden

5. Finales Annealing bei $55^{\circ} \mathrm{C}$

60 Sekunden

6. Finale Elongation bei $72{ }^{\circ} \mathrm{C}$

10 Minuten 
Die 2. - 4. werden in 35 Zyklen wiederholt. Die drei Phasen dieser Zyklen stellen folgende Prozesse dar:

- Denaturierung: Ziel ist es den DNA-Doppelstrang der Template-DNA in seine beiden Einzelstränge aufzutrennen

- Annealing: ermöglicht den Primern eine Anlagerung an die beiden Einzelstränge der Template-DNA

-Elongation: ermöglicht der Taq-Polymerase die Synthese eines neuen DNAStranges aus den zugegebenen dNTPs

\subsubsection{Auftrennung und Visualisierung der amplifizierten DNA mittels Agarosegelelektrophorese}

Der PCR schließt sich die Agarosegelelektrophorese an. Hierbei handelt es sich um ein Verfahren, welches die Auftrennung der während der PCR amplifizierten DNA nach deren Größe (in Basenpaaren) bzw. deren Molekulargewicht, ermöglicht. Agarosegele zeichnen sich durch eine netzartige Struktur auf molekularer Ebene aus, welche als Siebstruktur für Makromoleküle, wie beispielsweise DNA, fungiert. Für die im Rahmen dieser Arbeit durchgeführte Agarosegelelektrophorese wurde ein 1,5\% Gel mit $1 \mu \mathrm{g} / \mathrm{ml}$ Ethidiumbromid verwendet. Über dem Gel wurde eine elektrische Spannung angelegt. Da DNA, aufgrund ihrer zahlreichen Phosphatreste, negativ geladen ist, wandert sie durch das im elektrischen Feld befindliche Gel mithilfe eines 1X TAE-Laufpuffers in Richtung der Anode. Die elektrophoretische Mobilität der DNA-Stränge ist umgekehrt proportional zu ihrer molekularen Masse. DNA-Stränge gleicher Größe akkumulieren sich folglich auf gleicher Höhe innerhalb des Gels und bilden so charakteristische Banden, denen, nach der Verfärbung mit Ethidiumbromid, mittels eines Markers (z. B. PhiX174/ HaellI) eine bestimmte Länge (in Basenpaaren) zugeordnet werden kann. Der Farbstoff Ethidiumbromid interkaliert in Nucleinsäuren und weist eine starke Fluoreszenz-Emission bei Bestrahlung 
mit UV-Licht auf. Diese kann im Folgenden detektiert werden, wobei die DNA PMP22-transgener Ratten eine Bande bei 501 Basenpaaren bildet, während die DNA von Wildtyp-Ratten in diesem Versuchsaufbau keine spezifischen Banden bildet.

\subsubsection{Elektrophysiologische Untersuchungen}

Die nachfolgend geschilderten elektrophysiologischen Untersuchungen wurden von Dr. rer. nat. Robert Fledrich durchgeführt und die Rohdaten freundlicherweise zur Auswertung und graphischen Visualisierung innerhalb dieser Arbeit zur Verfügung gestellt.

Nach der Narkotisierung der Versuchstiere mit der o. g. Gebrauchslösung wurden der $N$. ischiadicus und der posteriore Abschnitt des $N$. tibialis mit Nadelelektroden, welche entlang der Nerven an der Incisura ischiadica major proximal im Bereich des Foramen ischiadicum und distal im Bereich des Sprunggelenks platziert wurden, stimuliert. Vor der Platzierung der Nadelelektroden und der nachfolgenden Stimulation wurde die Narkosetiefe mittels eines definierten mechanischen Schmerzreizes, in Form eines Pinzettenkniffs in die Interdigitalfalte des Hinterlaufs, überprüft. Die Narkosetiefe wurde als ausreichend bewertet, sofern der Flexorreflex des Hinterlaufs nicht durch den Pinzettenkniff ausgelöst wurde. Die Stimulation erfolgte mittels supramaximaler Rechteckimpulse (Impulsdauer $100 \mu \mathrm{s}$ ), welche von dem o.g. Elektrophysiologiegerät generiert wurden. Die proximalen CMAP wurden am Foramen ischiadicum und die distalen CMAP wurden am Sprunggelenk gemessen. Als Amplituden wurden die Spannungen detektiert, welche zwischen der Grundlinie und der gemessenen maximal negativen Auslenkung der Spannungskurve auftraten. Der Abstand zwischen der Reiz- und der Ableitelektrode (subkutane Nadelelektroden) wurde entlang der Hautoberfläche des vollständig ausgestreckten Hinterlaufes gemessen 
und die NLG nach Eingabe dieses Parameters automatisch als Latenzdifferenz ermittelt.

Mit den identischen Parametern der o. g. elektrophysiologischen Messungen wurden weitere Datensätze hinsichtlich NLG und CMAP an zwei definierten Punkten des Schwanzes mit einem Abstand von $2 \mathrm{~cm}$ durchgeführt. Mithilfe exogener Temperaturzufuhr konnte eine konstante Körpertemperatur von $37^{\circ} \mathrm{C}$ im Bereich des Schwanzes, welcher unter Narkose tendenziell hypothermisch ist, gewährleistet werden.

\subsubsection{Histologische Verfahren}

\subsubsection{Einbettung der Gewebeproben in Epon und Anfertigung von Semidünnschnitten bzw. Ultradünnschnitten}

Den Versuchstieren wurden jeweils zum Studienende der $N$. tibialis und andere Nerven entnommen. Vor der Gewebeentnahme wurden die Versuchstiere mithilfe von $\mathrm{CO}_{2}$-Gas geopfert. Nach seiner Entnahme wurde der $N$. tibialis in dreiprozentigem, phosphatgepufferten Glutaraldehyd (Karlsson und Schultz 1965) für eine Woche bei $4{ }^{\circ} \mathrm{C}$ immersionsfixiert.

Im Anschluss hieran wurden die Proben im Gewebeeinbettautomaten „LYNX EL" prozessiert, wobei der Fixation in einer $2 \%$ Osmium(VIII)-oxid-Lösung diverse Waschschritte in $\mathrm{dH}_{2} \mathrm{O}$, aufsteigenden Ethanolkonzentrationen (30100 \%), reinem Propylenoxid, Mischungen aus Propylenoxid und Epon (Verhältnisse: 2:1, 1:1, 1:2) und schließlich in reinem Epon folgten. Nach einer 24-stündigen Polymerisation des Epons, welches die stets gleich ausgerichteten Proben umschloss, entstanden Eponblöcke, welche für die weitere Verarbeitung genutzt wurden. Zur Herstellung von Semidünnschnitten am o.g. Rotationsmikroskop wurden die Eponblöcke vorerst am o. g. Probentrimmer in Form konvergierender Seitenkanten getrimmt. 
Am Rotationsmikrotom wurden nun Semidünnschnitte des Nervenquerschnitts mit einer Dicke von $500 \mathrm{~nm}$ und Ultradünnschnitte mit einer Dicke von $60 \mathrm{~nm}$ angefertigt. Nach ihrem Transfer auf die o. g. Objektträger wurden die Semidünnschnitte für eine Stunde bei $60^{\circ} \mathrm{C}$ getrocknet. Nach ihrem Transfer auf spezielle Kupfergitter, welche mit einer dünnen Formvarmembran beschichtet waren, wurden die Ultradünnschnitte ebenfalls getrocknet.

\subsubsection{Färbung der Semidünnschnitte für lichtmikroskopische Unter- suchungen}

Zur Färbung der auf den Objektträgern befindlichen Semidünnschnitte wurde die o. g. Methylen-Azur-II-Färbelösung verwendet. Es wurden die Objektträger im Bereich der Proben mit der Färbelösung beschickt und bei $60{ }^{\circ} \mathrm{C}$ für eine Minute inkubiert. Einem Spülschritt mit $\mathrm{dH}_{2} \mathrm{O}$ folgte eine 10-minütige Trocknung bei $60{ }^{\circ} \mathrm{C}$ sowie eine anschließende Eindeckung der Probe mit EUKITT®.

\subsubsection{Lichtmikroskopische Untersuchung und Axonquantifizierung}

Die Semidünnschnitte wurden schließlich am Lichtmikroskop in 100-facher Vergrößerung untersucht und mit einer Mikroskopkamera abfotografiert. Aus einer unterschiedlich großen Anzahl an Einzelbildern pro Probe wurde nun mithilfe der o.g. Software für Mikroskopkameras ein Vollbild der jeweiligen Probe zusammengesetzt.

Die Axonquantifizierung, also die Auszählung aller Axone (>1 $\mu \mathrm{m}$ im $\emptyset)$ des jeweilig angeschnittenen Nervenquerschnitts, erfolgte für jede Probe von demselben, für alle Experimente geblindeten Untersucher mithilfe der Software Image J (s. o.). 


\subsubsection{Kontrastierung der Ultradünnschnitte für elektronen- mikroskopische Untersuchungen}

Die Ultradünnschnitte wurden nach ihrer Trocknung zwei Kontrastierungsschritten unterzogen. Einem ersten Schritt, bei dem die Schnitte für 30 min mit $2 \%$ iger Uranylacetatlösung versetzt wurden, folgte nach einer Zwischenspülung mit $\mathrm{H}_{2} \mathrm{O}$ die finale 6-minütige Kontrastierung mit Bleicitrat (Reynolds 1963).

\subsubsection{Elektronenmikroskopische Untersuchung}

Die Semidünnschnitte wurden schließlich am Elektronenmikroskop in 3000facher Vergrößerung untersucht und mit einer Mikroskopkamera abfotografiert. Hierbei entstanden pro Probe ungefähr 20 Einzelbilder, die randomisiert über die Probe verteilt geschossen wurden.

Die Messung des G-ratio, also des Verhältnisses des Innendurchmessers zum Außendurchmesser der Myelinscheide, erfolgte für jede Probe von demselben, für alle Experimente geblindeten Untersucher mithilfe der Software Image J (s. o.). Pro Probe wurde die Messung des G-ratio an $\geq 100$ Axonen durchgeführt.

\subsubsection{Statistik}

Alle gesammelten Datensätze wurden mit Excel® für Mac (s. o.) verwaltet und z. T. auch statistisch ausgewertet sowie graphisch visualisiert. Für weitergehende statistische Analysen wurde die Software IBM ${ }^{\circledR}$ SPSS $\circledast$ Statistics (s. o.) verwandt. So wurde der Kolmogorov-Smirnov-Test hinsichtlich einer Prüfung der Datensätze auf eine Normalverteilung angewandt. Da alle Datensätze eine Normalverteilung aufwiesen, wurde anschließend der 
zweiseitige t-Test auf sie angewandt, um statistische Unterschiede zu analysieren. Im Falle der Datensätze der Studie mit frühem Behandlungsbeginn wurde eine Einweg-Varianzanalyse (ANOVA Dunnett-Test (2-seitig)) durchgeführt, da die Zielvariablen (z. B. Griffstärke) von den Einflussvariablen (hier die Dosis von L-a-Phosphatidylcholin) abhing.

Hinsichtlich der Signifikanz statistischer Unterschiede wurden diese als signifikant festgelegt sofern der $\mathrm{p}$-Wert $<0,05$ war. Es wurden folgende Graduierungen der Signifikanz, welche durch die Verwendung von Sternchen visualisiert wurden, vorgenommen: ${ }^{*} p<0,05,{ }^{* *} p<0,01,{ }^{* * *} p<0,001$ 


\section{Ergebnisse}

\subsection{Phänotypische Untersuchungen}

\subsubsection{Griffstärke der Hinterläufe}

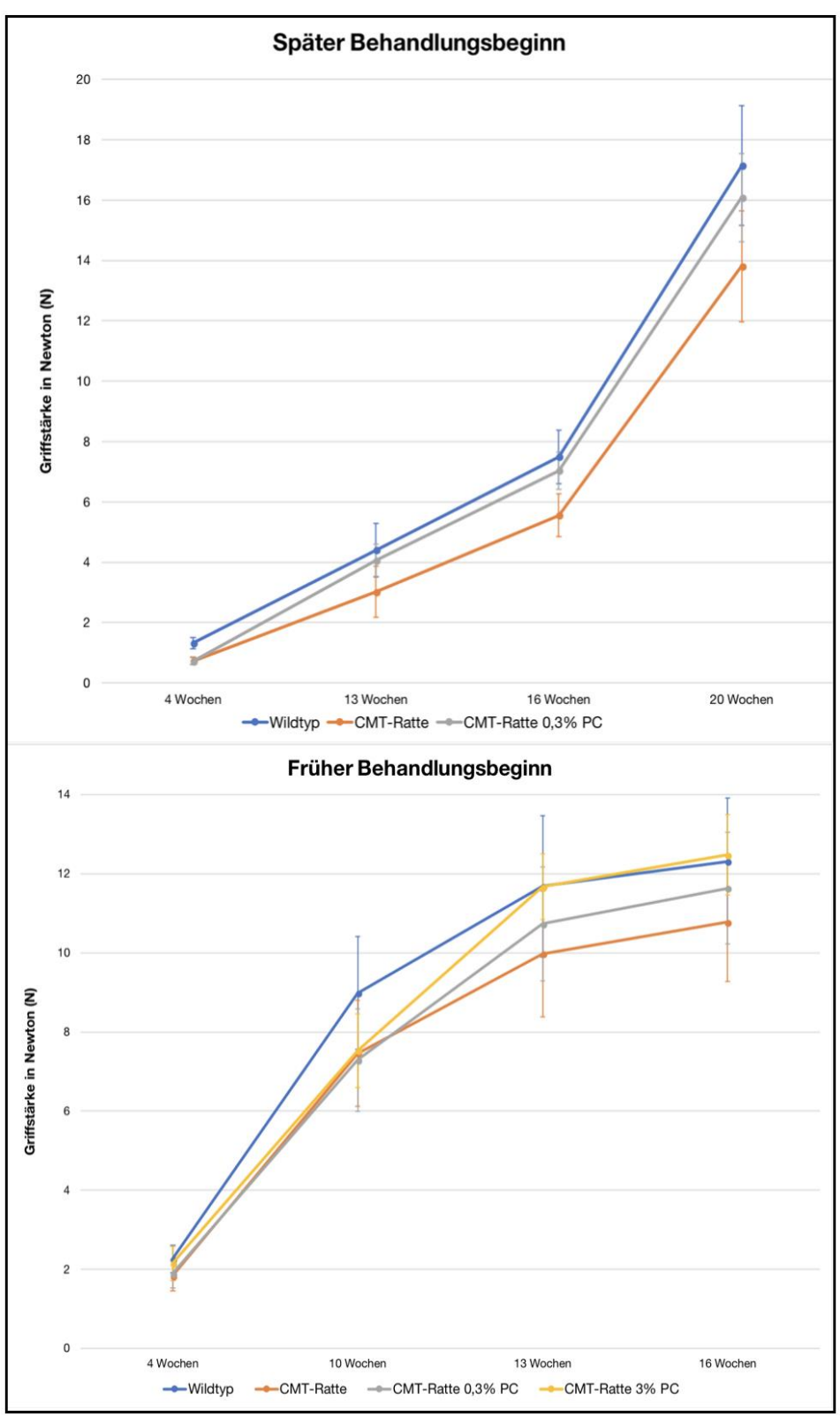

Tab. 14: Griffstärke Hinterläufe

\begin{tabular}{|c|c|}
\hline $\begin{array}{l}\text { Gruppen (später Behandlungs- } \\
\text { beginn) }\end{array}$ & $\begin{array}{l}\text { t- } \\
\text { Test }\end{array}$ \\
\hline \multicolumn{2}{|l|}{4 Wochen } \\
\hline Wildtyp/ CMT-Ratte & 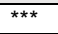 \\
\hline Wildtyp/ CMT-Ratte $0,3 \%$ PC & $* \star *$ \\
\hline CMT-Ratte/ CMT-Ratte 0,3\% PC & n. s. \\
\hline \multicolumn{2}{|l|}{13 Wochen } \\
\hline Wildtyp/ CMT-Ratte & $* \star * *$ \\
\hline Wildtyp/ CMT-Ratte $0,3 \%$ PC & n.s. \\
\hline CMT-Ratte/ CMT-Ratte 0,3\% PC & $* \star *$ \\
\hline \multicolumn{2}{|l|}{16 Wochen } \\
\hline Wildtyp/ CMT-Ratte & $* \star * \star$ \\
\hline Wildtyp/ CMT-Ratte $0,3 \%$ PC & n. s. \\
\hline CMT-Ratte/ CMT-Ratte 0,3\% PC & $* \star *$ \\
\hline \multicolumn{2}{|l|}{20 Wochen } \\
\hline Wildtyp/ CMT-Ratte & $\star \star \star \star *$ \\
\hline Wildtyp/ CMT-Ratte $0,3 \%$ PC & n.s. \\
\hline CMT-Ratte/ CMT-Ratte 0,3\% PC & 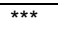 \\
\hline
\end{tabular}

\begin{tabular}{|l|l|}
\hline Gruppen (früher & ANOVA \\
\hline
\end{tabular}
Behandlungs-

beginn)

4 Wochen

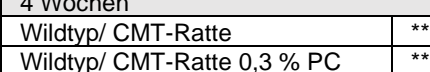

\begin{tabular}{|l|l}
\hline Wildtyp/ CMT-Ratte 3\% PC & n. s. \\
\hline CMT-Ratte/ CMT-Ratte 0,3\% PC & n. s. \\
\hline
\end{tabular}

CMT-Ratte/ CMT-Ratte 3\% PC 1 n. s.

10 Wochen

\begin{tabular}{|l|l}
\hline Wildtyp/ CMT-Ratte & ** \\
\hline Wildtyp/ CMT-Ratte 0,3\% PC & ** \\
\hline Widtyp/ CMT-Ratte $3 \%$ PC & $* \star$
\end{tabular}

Wildtyp/ CMT-Ratte $3 \%$ PC

\begin{tabular}{ll} 
CMT-Ratte/ CMT-Ratte 0,3\% PC & n. s. \\
\hline
\end{tabular}

\begin{tabular}{ll}
\hline CMT-Ratte/ CMT-Ratte 3\% PC & n. s. \\
\hline
\end{tabular}

13 Wochen

Wildtyp/ CMT-Ratte

\begin{tabular}{|l|l}
\hline Wildtyp/ CMT-Ratte 0,3\% PC & n. s. \\
\hline WidtyP/ CMT-Ratt $3 \%$ PC & n. s.
\end{tabular}

$\begin{array}{ll}\text { Wildtyp/ CMT-Ratte 3\% PC } & \text { n. s. }\end{array}$

CMT-Ratte/ CMT-Ratte 0,3\% PC n. s.

CMT-Ratte/ CMT-Ratte $3 \%$ PC

16 Wochen

\begin{tabular}{|l|l}
\hline Wildtyp/ CMT-Ratte & ${ }^{\star \star}$ \\
\hline Wildtyp/ CMT-Ratte 0,3\% PC & n. s. \\
\hline Wildtyp/ CMT-Ratte $\% \%$ PC & n. s.
\end{tabular}

\begin{tabular}{|l|l}
\hline Wildtyp/ CMT-Ratte 0,3 \% PC & n. s. \\
\hline Wildtyp/ CMT-Ratte 3\% PC & n. s. \\
\hline
\end{tabular}

\begin{tabular}{ll} 
CMT-Ratte/ CMT-Ratte 0,3\% PC & n. s. \\
\hline
\end{tabular}

\begin{tabular}{ll|l}
\hline CMT-Ratte/ CMT-Ratte 3\% PC & ** \\
\hline
\end{tabular}

Abb. 4: Verlaufsdiagramm zur Griffstärke der Hinterläufe

Wildtyp: Wildtyp-Ratten mit Spezialdiät für Ratten ohne Zusätze (Placebo) gefüttert; CMT-Ratte: CMT-Ratten mit Spezialdiät für Ratten ohne Zusätze (Placebo) gefüttert; CMT-Ratte 0,3 \% PC: CMT-Ratten mit Spezialdiät für Ratten und einem Zusatz von 0,3 Gew.-\% L-a-Phosphatidylcholin gefüttert; CMT-Ratte 3 \% PC: CMT-Ratten mit Spezialdiät für Ratten und einem Zusatz von 3,0 Gew.-\% L- $\alpha$-Phosphatidylcholin gefüttert; Fehlerindikatoren: es wird die Standardabweichung angegeben; t-Test: *: p-Wert $<0,05 ;{ }^{* *}$ : $p$-Wert $<0,01 ;{ }^{* * *}$ : p-Wert $<0,001$; ANOVA DunnettTest (2-seitig): *: p-Wert <0,05; **: p-Wert <0,01; ***: p-Wert <0,001 


\section{Ergebnisse}
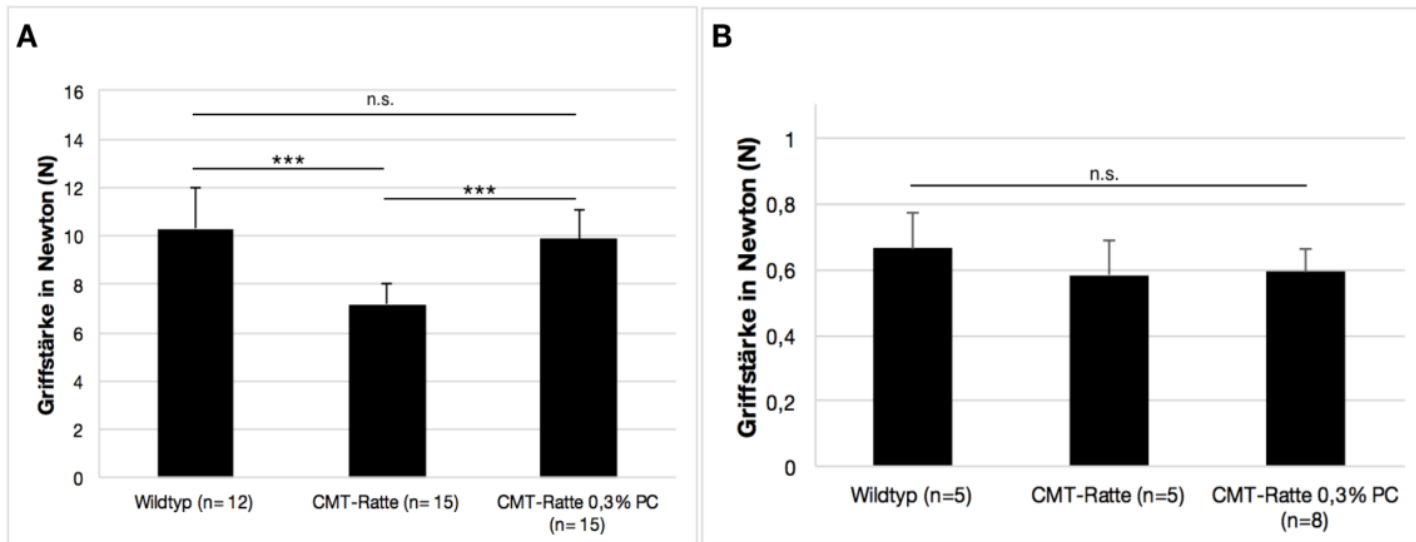

C

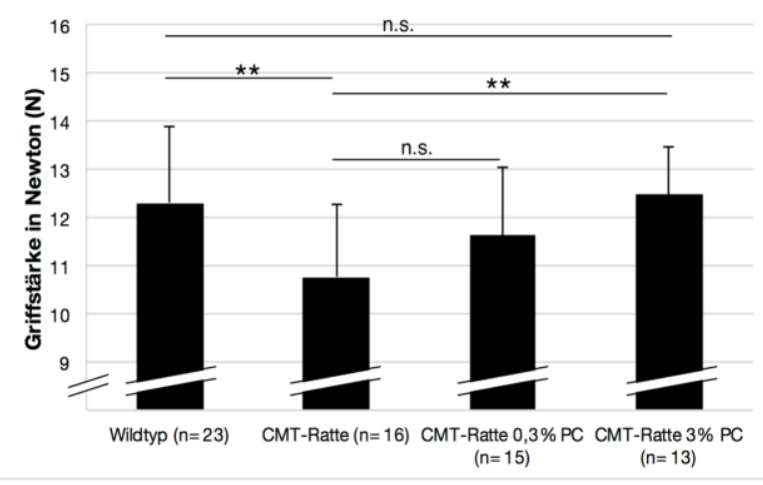

Abb. 5: Griffstärke der Hinterläufe zum jeweiligen Studienende

A: Später Therapiebeginn; B: Früher Therapiebeginn Kurzzeitstudie; C: Früher Therapiebeginn; Wildtyp: WildtypRatten mit Spezialdiät für Ratten ohne Zusätze (Placebo) gefüttert; CMT-Ratte: CMT-Ratten mit Spezialdiät für Ratten ohne Zusätze (Placebo) gefüttert; CMT-Ratte 0,3 \% PC: CMT-Ratten mit Spezialdiät für Ratten und einem Zusatz von 0,3 Gew.-\% L- $\alpha$-Phosphatidylcholin gefüttert; CMT-Ratte 3 \% PC: CMT-Ratten mit Spezialdiät für Ratten und einem Zusatz von 3,0 Gew.-\% L-a-Phosphatidylcholin gefüttert; Fehlerindikatoren: es wird die Standardabweichung angegeben; t-Test: *: p-Wert < 0,05; **: p-Wert <0,01; ***: p-Wert <0,001; ANOVA DunnettTest (2-seitig): *: p-Wert $<0,05 ;{ }^{* *}$ : p-Wert $<0,01 ;{ }^{* * *}$ : p-Wert $<0,001$

\subsubsection{Später Therapiebeginn}

Das wie zuvor beschrieben supplementierte L- $\alpha$-Phosphatidylcholin ist in der Lage die Griffstärke der Hinterläufe als Therapieerfolg zum Ende der Therapiestudie (Alter der Versuchstiere: 20 Wochen) zu verbessern. Die Dosis von 0,3 Gew.-\% L-a-Phosphatidylcholin führt zu einer signifikanten Erhöhung $(p=0,0008)$ der Griffstärke der Hinterläufe der therapierten CMT-Ratten im Vergleich zu der Griffstärke der Hinterläufe der mit einem Placebo behandelten CMT-Ratten, wobei die Griffstärke der Hinterläufe der therapierten CMT-Ratten das Niveau $(p=0,12)$ der Wildtyp-Ratten erreicht. 


\subsubsection{Früher Therapiebeginn (Kurzzeitstudie)}

In dieser Therapiestudie konnte die typischerweise zu erwartende signifikante Reduktion der Griffstärke der Hinterläufe bei der CMT-Ratte nicht festgestellt werden. Die statistischen Unterschiede zwischen allen Gruppen sind nicht signifikant.

\subsubsection{Früher Therapiebeginn}

Das wie zuvor beschrieben supplementierte L-a-Phosphatidylcholin ist in der Lage die Griffstärke der Hinterläufe als Therapieerfolg zum Ende der Therapiestudie (Alter der Versuchstiere: 16 Wochen) dosisabhängig zu verbessern. Eine Dosis von 3,0 Gew.-\% L-a-Phosphatidylcholin führt zu einer signifikanten Erhöhung ( $p=0,009)$ der Griffstärke der Hinterläufe der therapierten CMT-Ratten im Vergleich zur Griffstärke der Hinterläufe der mit einem Placebo behandelten CMT-Ratten, wobei die Griffstärke der Hinterläufe der therapierten CMT-Ratten das Niveau $(p=0,98)$ der Wildtyp-Ratten erreicht. Die Erhöhung der Griffstärke bei einer Dosis von 0,3 Gew.-\% L-aPhosphatidylcholin verbleibt hingegen nicht signifikant $(p=0,29)$. 


\section{Ergebnisse}

\subsubsection{Griffstärke der Vorderläufe}

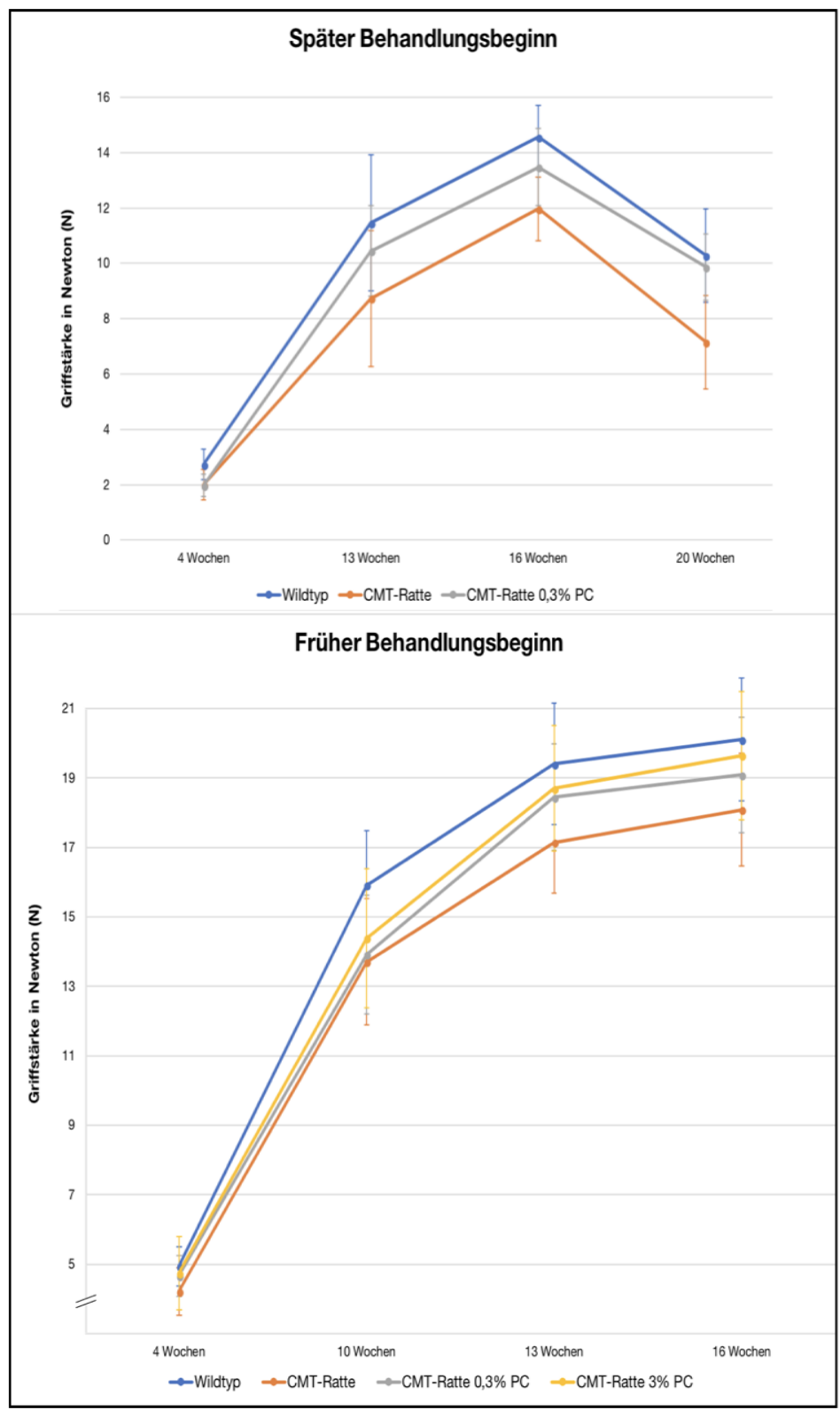

Tab. 15: Griffstärke Vorderläufe

\begin{tabular}{|c|c|}
\hline $\begin{array}{l}\text { Gruppen (später Behandlungs- } \\
\text { beginn) }\end{array}$ & $\begin{array}{l}\text { t- } \\
\text { Test }\end{array}$ \\
\hline \multicolumn{2}{|l|}{4 Wochen } \\
\hline Wildtyp/ CMT-Ratte & *** \\
\hline Wildtyp/ CMT-Ratte 0,3\% PC & $* \star *$ \\
\hline CMT-Ratte/ CMT-Ratte 0,3 \% PC & n.s. \\
\hline \multicolumn{2}{|l|}{13 Wochen } \\
\hline Wildtyp/ CMT-Ratte & ** \\
\hline Wildtyp/ CMT-Ratte 0,3 \% PC & n. s. \\
\hline CMT-Ratte/ CMT-Ratte 0,3 \% PC & ** \\
\hline \multicolumn{2}{|l|}{16 Wochen } \\
\hline Wildtyp/ CMT-Ratte & *** \\
\hline Wildtyp/ CMT-Ratte 0,3 \% PC & * \\
\hline CMT-Ratte/ CMT-Ratte 0,3 \% PC & ** \\
\hline \multicolumn{2}{|l|}{20 Wochen } \\
\hline Wildtyp/ CMT-Ratte & $\star * \star *$ \\
\hline Wildtyp/ CMT-Ratte 0,3 \% PC & n. s. \\
\hline CMT-Ratte/ CMT-Ratte 0,3 \% PC & *** \\
\hline
\end{tabular}

\begin{tabular}{|l|l|}
\hline Gruppen (früher & ANOVA \\
\hline
\end{tabular}

Behandlungs-

beginn)

4 Wochen

\begin{tabular}{|l|l|}
\hline Wildtyp/ CMT-Ratte & ** \\
\hline Widtyp/ CMT-Ratte $0,3 \%$ PC & n. s. \\
\hline
\end{tabular}

\begin{tabular}{l|l}
\hline Wildtyp/ CMT-Ratte 0,3\% PC & n. s.
\end{tabular}

\begin{tabular}{|l|l}
\hline Wildtyp/ CMT-Ratte 3\% PC & n. s. \\
\hline
\end{tabular}

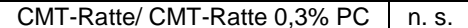

CMT-Ratte/ CMT-Ratte 3\% PC n. s.

10 Wochen

\begin{tabular}{|l|l|}
\hline Wildtyp/ CMT-Ratte $0,3 \%$ PC & $* \star *$ \\
\hline
\end{tabular}

Wildtyp/ CMT-Ratte 3\% PC

\begin{tabular}{ll} 
CMT-Ratte/ CMT-Ratte 0,3\% PC & n. s. \\
\hline
\end{tabular}

CMT-Ratte/ CMT-Ratte $3 \%$ PC 1 n. s.

13 Wochen

Wildtyp/ CMT-Ratte

\begin{tabular}{ll|l} 
Wildtyp/ CMT-Ratte 0,3 \% PC & n. s.
\end{tabular}

\begin{tabular}{|l|l}
\hline Wildtyp/ CMT-Ratte 3\% PC & n. s.
\end{tabular}

\begin{tabular}{|l|l} 
Wildtyp/ CMT-Ratte 3\% PC & n. \\
\hline CMT-Ratte/ CMT-Ratte 0,3\% PC & ${ }^{*}$ \\
\hline
\end{tabular}

CMT-Ratte/ CMT-Ratte 3\% PC *

16 Wochen

Wildtyp/ CMT-Ratte

\begin{tabular}{|l|l} 
Wildtyp/ CMT-Ratte & *** \\
\hline Wildtyp/ CMT-Ratte 0,3 \% PC & n. s.
\end{tabular}

$\begin{array}{ll}\text { Wildtyp/ CMT-Ratte 3\% PC } & \text { n. s. }\end{array}$

CMT-Ratte/ CMT-Ratte 0,3\% PC n. s.

CMT-Ratte/ CMT-Ratte 3\% PC *

Abb. 6: Verlaufsdiagramm zur Griffstärke der Vorderläufe

Wildtyp: Wildtyp-Ratten mit Spezialdiät für Ratten ohne Zusätze (Placebo) gefüttert; CMT-Ratte: CMT-Ratten mit Spezialdiät für Ratten ohne Zusätze (Placebo) gefüttert; CMT-Ratte 0,3% PC: CMT-Ratten mit Spezialdiät für Ratten und einem Zusatz von 0,3 Gew.-\% L- $\alpha$-Phosphatidylcholin gefüttert; CMT-Ratte 3 \% PC: CMT-Ratten mit Spezialdiät für Ratten und einem Zusatz von 3,0 Gew.-\% L-a-Phosphatidylcholin gefüttert; Fehlerindikatoren: es wird die Standardabweichung angegeben; t-Test: ${ }^{*}$ : p-Wert $<0,05 ;{ }^{* *}$ : $p-$ Wert $<0,01 ;{ }^{* * *}$ : p-Wert $<0,001$; ANOVA Dunnett-Test (2-seitig): *: p-Wert $<0,05 ;{ }^{* *}$ : p-Wert $<0,01 ;{ }^{* * *}$ : $p$-Wert $<0,001$ 


\section{Ergebnisse}

A

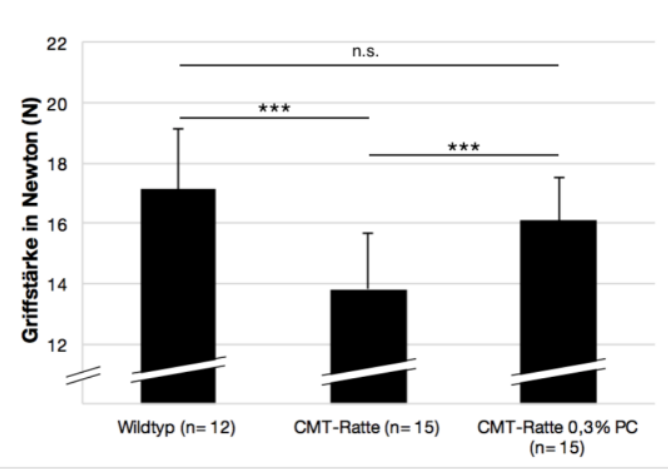

B

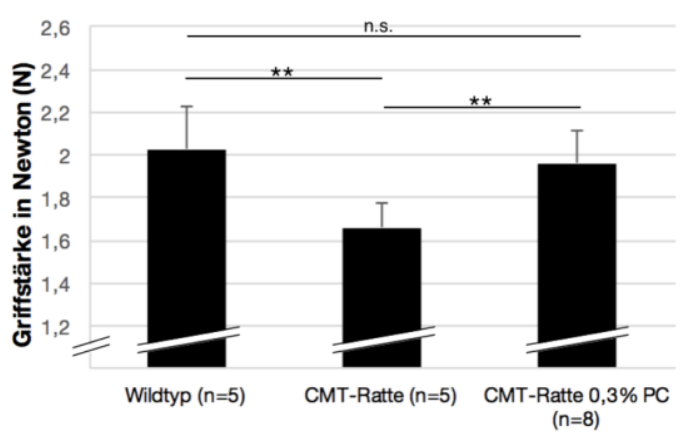

C

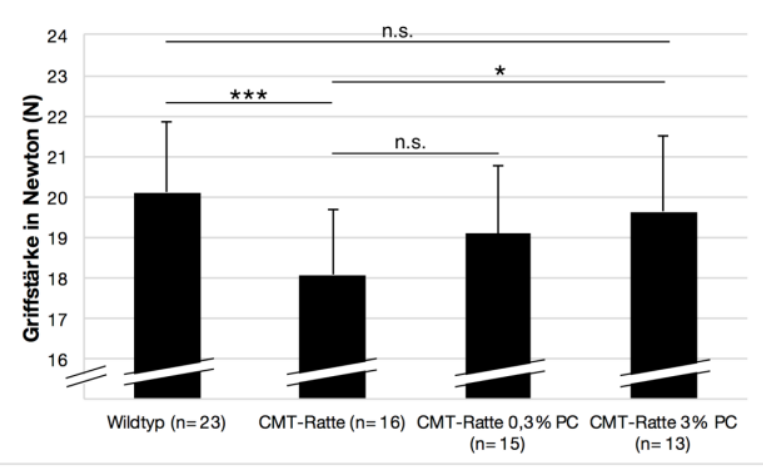

Abb. 7: Griffstärke der Vorderläufe zum jeweiligen Studienende

A: Später Therapiebeginn; B: Früher Therapiebeginn Kurzzeitstudie; C: Früher Therapiebeginn; Wildtyp: WildtypRatten mit Spezialdiät für Ratten ohne Zusätze (Placebo) gefüttert; CMT-Ratte: CMT-Ratten mit Spezialdiät für Ratten ohne Zusätze (Placebo) gefüttert; CMT-Ratte 0,3 \% PC: CMT-Ratten mit Spezialdiät für Ratten und einem Zusatz von 0,3 Gew.-\% L- $\alpha$-Phosphatidylcholin gefüttert; CMT-Ratte 3 \% PC: CMT-Ratten mit Spezialdiät für Ratten und einem Zusatz von 3,0 Gew.-\% L- $\alpha$-Phosphatidylcholin gefüttert; Fehlerindikatoren: es wird die Standardabweichung angegeben; t-Test: ${ }^{*}$ : $p$-Wert $<0,05 ;{ }^{* *}$ : $p$-Wert $<0,01 ;{ }^{* * *}$ : $p$-Wert $<0,001$; ANOVA DunnettTest (2-seitig): *: p-Wert <0,05; ${ }^{* *}$ : p-Wert $<0,01 ;{ }^{* * *}$ : $p$-Wert $<0,001$

\subsubsection{Später Therapiebeginn}

Das wie zuvor beschrieben supplementierte L- $\alpha$-Phosphatidylcholin ist in der Lage die Griffstärke der Vorderläufe als Therapieerfolg zum Ende der Therapiestudie (Alter der Versuchstiere: 20 Wochen) zu verbessern. Eine Dosis von 0,3 Gew.-\% L-a-Phosphatidylcholin führt zu einer signifikanten Erhöhung ( $p=0,0000001)$ der Griffstärke der Vorderläufe der therapierten CMT-Ratten im Vergleich zur Griffstärke der Vorderläufe der mit einem Placebo behandelten CMT-Ratten, wobei die Griffstärke der Hinterläufe der therapierten CMT-Ratten das Niveau $(p=0,45)$ der Wildtyp-Ratten erreicht. 


\subsubsection{Früher Therapiebeginn (Kurzzeitstudie)}

Das, wie zuvor beschrieben, supplementierte L- $\alpha$-Phosphatidylcholin ist in der Lage die Griffstärke der Vorderläufe als Therapieerfolg zum Ende der Therapiestudie (Alter der Versuchstiere: 18. Postnataltag) zu verbessern. Eine Dosis von 0,3 Gew.-\% L-a-Phosphatidylcholin führt zu einer signifikanten Erhöhung $(p=0,003)$ der Griffstärke der Vorderläufe der therapierten CMTRatten im Vergleich zur Griffstärke der Vorderläufe der mit einem Placebo behandelten CMT-Ratten, wobei die Griffstärke der Vorderläufe der therapierten CMT-Ratten das Niveau $(p=0,48)$ der Wildtyp-Ratten erreicht.

\subsubsection{Früher Therapiebeginn}

Das, wie zuvor beschrieben, supplementierte L- $\alpha$-Phosphatidylcholin ist in der Lage die Griffstärke der Vorderläufe als Therapieerfolg zum Ende der Therapiestudie (Alter der Versuchstiere: 16 Wochen) dosisabhängig zu verbessern. Eine Dosis von 3,0 Gew.-\% L-a-Phosphatidylcholin führt zu einer signifikanten Erhöhung $(p=0,009)$ der Griffstärke der Vorderläufe der therapierten CMT-Ratten im Vergleich zur Griffstärke der Vorderläufe der mit einem Placebo behandelten CMT-Ratten, wobei die Griffstärke der Vorderläufe der therapierten CMT-Ratten das Niveau $(p=0,817)$ der WildtypRatten erreicht. Die Erhöhung der Griffstärke der Vorderläufe bei einer Dosis von 0,3 Gew.-\% L- $\alpha$-Phosphatidylcholin verbleibt hingegen nicht signifikant $(p=0,257)$. 


\section{Ergebnisse}

\subsubsection{Körpergewicht}

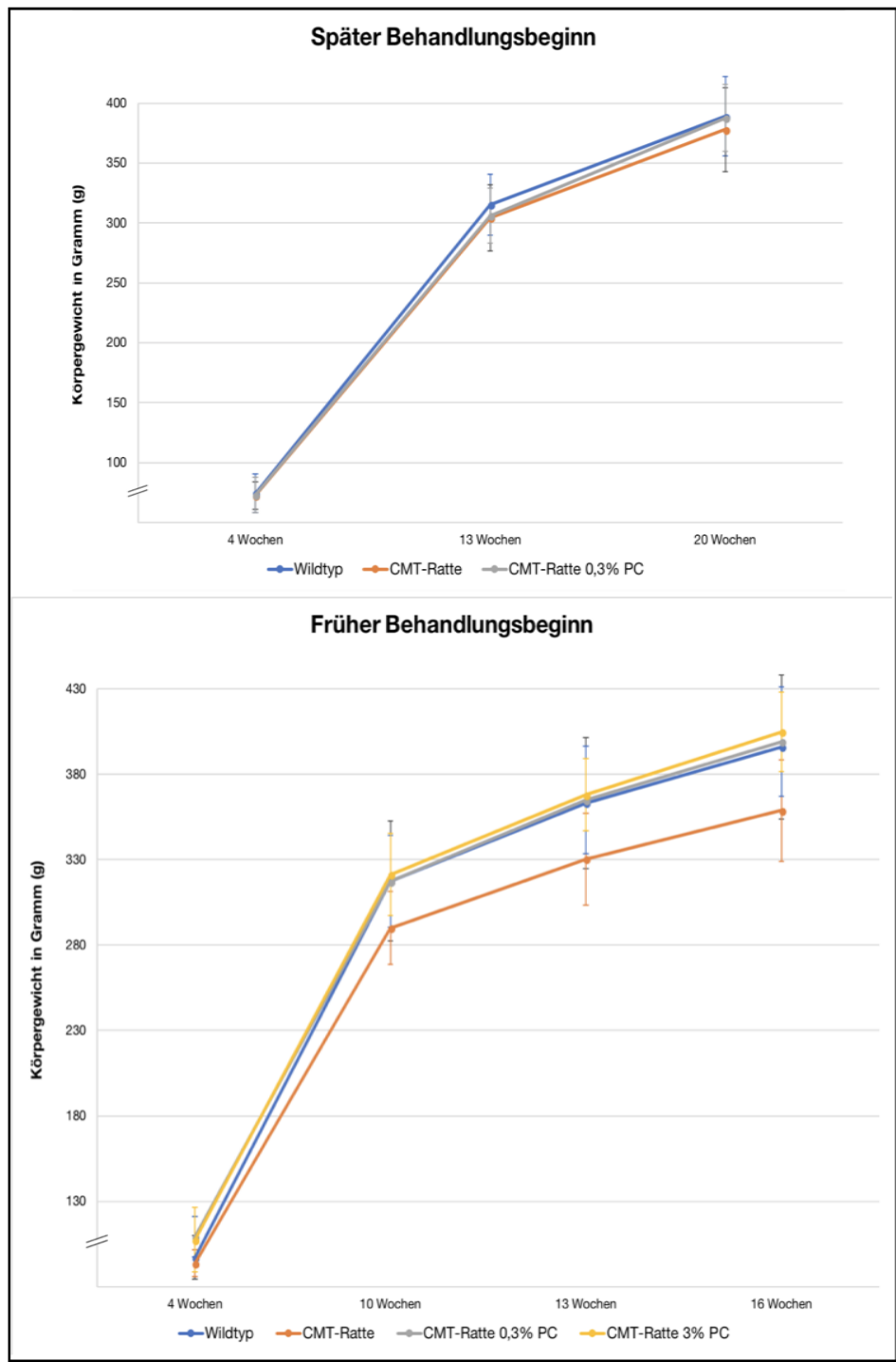

Tab. 16: Körpergewicht

\begin{tabular}{|l|l|}
\hline $\begin{array}{l}\text { Gruppen (später Behandlungs- } \\
\text { beginn) }\end{array}$ & $\begin{array}{l}\text { t- } \\
\text { Test }\end{array}$ \\
\hline 4 Wochen & n. s. \\
\hline Wildtyp/ CMT-Ratte & n. s. \\
\hline Wildtyp/ CMT-Ratte 0,3\% PC & n. s. \\
\hline CMT-Ratte/ CMT-Ratte 0,3\% PC & n. s. \\
\hline 13 Wochen & n. s. \\
\hline Wildtyp/ CMT-Ratte & n. s. \\
\hline Wildtyp/ CMT-Ratte 0,3\% PC \\
\hline CMT-Ratte/ CMT-Ratte 0,3\% PC & n. s. \\
\hline 20 Wochen & n. s. \\
\hline Wildtyp/ CMT-Ratte & n. s. \\
\hline Wildtyp/ CMT-Ratte 0,3\% PC \\
\hline CMT-Ratte/ CMT-Ratte 0,3\% PC
\end{tabular}

\begin{tabular}{|l|l|}
\hline Gruppen (früher & ANOVA \\
\hline
\end{tabular}

Behandlungs-

beginn)

4 Wochen

\begin{tabular}{|l|l|}
\hline Wildtyp/ CMT-Ratte & n. s. \\
\hline Wildtyp/ CMT-Ratte $0,3 \%$ PC & $\star \star$
\end{tabular}

Wildtyp/CMT-Ratte 3\% PC

\begin{tabular}{l|l}
\hline Wildtyp/ CMT-Ratte 3 \% PC & n. s. \\
\hline CMT-Ratte/ CMT-Ratte 0,3\% PC & ${ }^{\star \star \star}$ \\
\hline CMT-Ratte/ CMT-Ratte 3\% PC & *
\end{tabular}

CMT-Ratte/ CMT-Ratte 3\% PC

10 Wochen

\begin{tabular}{|l|l}
\hline Wildtyp/ CMT-Ratte & ${ }^{* \star}$ \\
\hline Wildtyp/ CMT-Ratte 0,3 \% PC & n. s. \\
\hline Wildtyp/ CMT-Ratte $3 \%$ PC & n. s.
\end{tabular}

Wildtyp/ CMT-Ratte 3\% PC

\begin{tabular}{ll}
\hline CMT-Ratte/ CMT-Ratte 0,3\% PC & ** \\
\hline
\end{tabular}

\begin{tabular}{l} 
CMT-Ratte/ CMT-Ratte 0,3\% PC \\
\hline CMT-Ratte/ CMT-Ratte 3 \% PC
\end{tabular}

13 Wochen

Wildtyp/ CMT-Ratte

Wildtyp/ CMT-Ratte 0,3\% PC

Wildtyp/ CMT-Ratte 3\% PC

CMT-Ratte/ CMT-Ratte 0,3\% PC

CMT-Ratte/ CMT-Ratte $3 \%$ PC

16 Wochen

Wildtyp/ CMT-Ratte

\begin{tabular}{l|l} 
Wildtyp/ CMT-Ratte $0,3 \%$ PC & n. s. \\
\hline Wildyp/ CMT-Ratte $3 \%$ PC & n. s. \\
\hline
\end{tabular}

\begin{tabular}{l|l} 
Wildtyp/ CMT-Ratte $3 \%$ PC & n. s. \\
\hline
\end{tabular}

\begin{tabular}{l|l} 
CMT-Ratte/ CMT-Ratte 0,3\% PC & ** \\
\hline CMT-Ratte/CMT-Ratte 3\% PC & $* \star \star$ \\
\hline
\end{tabular}

CMT-Ratte/ CMT-Ratte $3 \%$ PC

Abb. 8: Verlaufsdiagramm zum Körpergewicht

Wildtyp: Wildtyp-Ratten mit Spezialdiät für Ratten ohne Zusätze (Placebo) gefüttert; CMT-Ratte: CMT-Ratten mit Spezialdiät für Ratten ohne Zusätze (Placebo) gefüttert; CMT-Ratte 0,3 \% PC: CMT-Ratten mit Spezialdiät für Ratten und einem Zusatz von 0,3 Gew.-\% L- $\alpha$-Phosphatidylcholin gefüttert; CMT-Ratte 3 \% PC: CMT-Ratten mit Spezialdiät für Ratten und einem Zusatz von 3,0 Gew.-\% L- $\alpha$-Phosphatidylcholin gefüttert; Fehlerindikatoren: es wird die Standardabweichung angegeben; t-Test: *: $p$-Wert $<0,05 ;{ }^{* *}$ : $p$-Wert $<0,01 ;{ }^{* * *}$ : $p$-Wert $<0,001$; ANOVA Dunnett-Test (2-seitig): *: p-Wert $<0,05 ;{ }^{* *}$ : p-Wert $<0,01 ;{ }^{* * *}$ : p-Wert $<0,001$ 


\section{Ergebnisse}

A

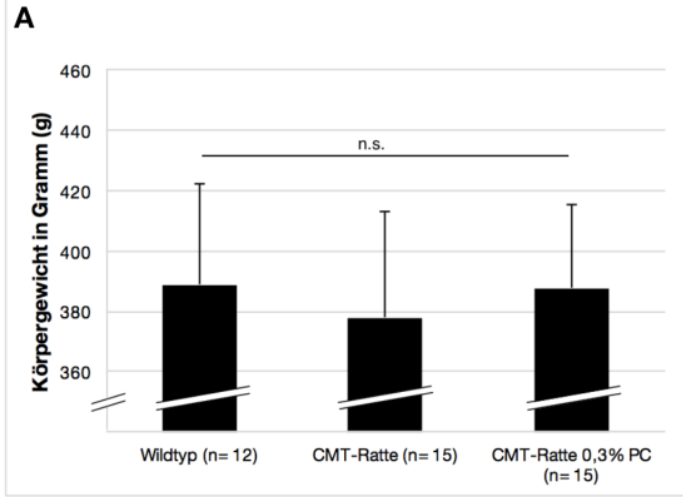

B

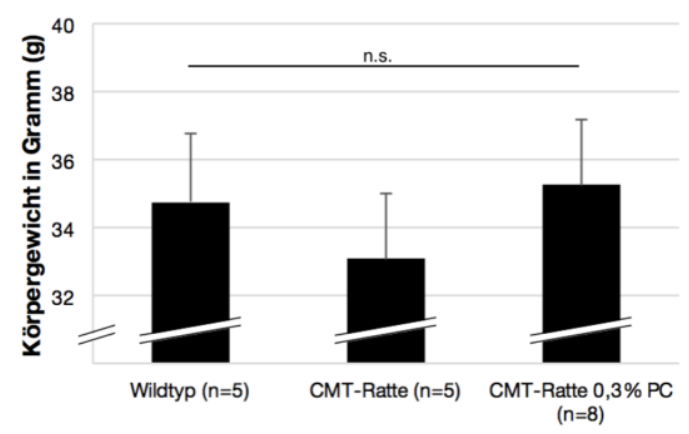

C

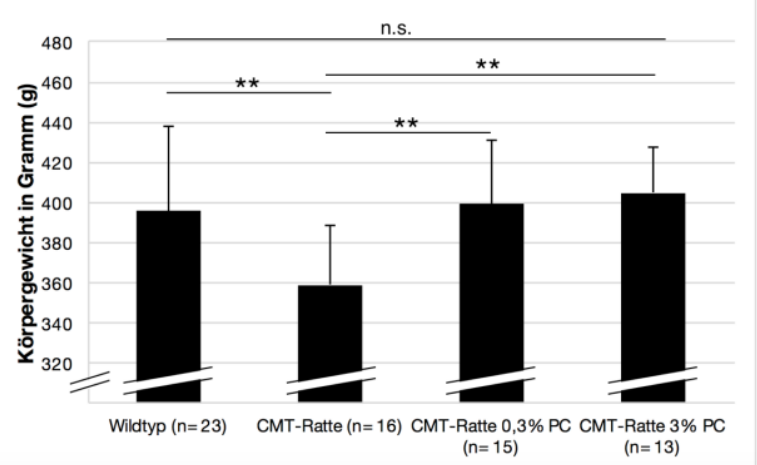

Abb. 9: Körpergewicht zum jeweiligen Studienende

A: Später Therapiebeginn; B: Früher Therapiebeginn Kurzzeitstudie; C: Früher Therapiebeginn; Wildtyp: WildtypRatten mit Spezialdiät für Ratten ohne Zusätze (Placebo) gefüttert; CMT-Ratte: CMT-Ratten mit Spezialdiät für Ratten ohne Zusätze (Placebo) gefüttert; CMT-Ratte 0,3 \% PC: CMT-Ratten mit Spezialdiät für Ratten und einem Zusatz von 0,3 Gew.-\% L-a-Phosphatidylcholin gefüttert; CMT-Ratte 3 \% PC: CMT-Ratten mit Spezialdiät für Ratten und einem Zusatz von 3,0 Gew.-\% L-a-Phosphatidylcholin gefüttert; Fehlerindikatoren: es wird die Standardabweichung angegeben; t-Test: *: p-Wert $<0,05 ;{ }^{* *}$ : $p$-Wert $<0,01 ;{ }^{* * *}$ : $p$-Wert $<0,001$; ANOVA DunnettTest (2-seitig): *: p-Wert <0,05; ${ }^{* *}$ : p-Wert $<0,01 ;{ }^{* * *}$ : p-Wert $<0,001$

\subsubsection{Später Therapiebeginn}

In dieser Therapiestudie konnte die typischerweise zu erwartende signifikante Reduktion des Körpergewichtes bei der CMT-Ratte nicht festgestellt werden. Die statistischen Unterschiede zwischen allen Gruppen sind nicht signifikant.

\subsubsection{Früher Therapiebeginn (Kurzzeitstudie)}

In dieser Therapiestudie konnte die typischerweise zu erwartende signifikante Reduktion des Körpergewichtes bei der CMT-Ratte nicht festgestellt werden. Die statistischen Unterschiede zwischen allen Gruppen sind nicht signifikant. 


\subsubsection{Früher Therapiebeginn}

Das wie zuvor beschrieben supplementierte L-a-Phosphatidylcholin ist in der Lage das Körpergewicht als Therapieerfolg zum Ende der Therapiestudie (Alter der Versuchstiere: 16 Wochen) dosisunabhängig zurück auf das Niveau ( $p=0,814-0,987)$ von Wildtyp-Ratten zu heben.

\subsection{Neurophysiologische Untersuchungen}

\subsubsection{Nervenleitgeschwindigkeit}
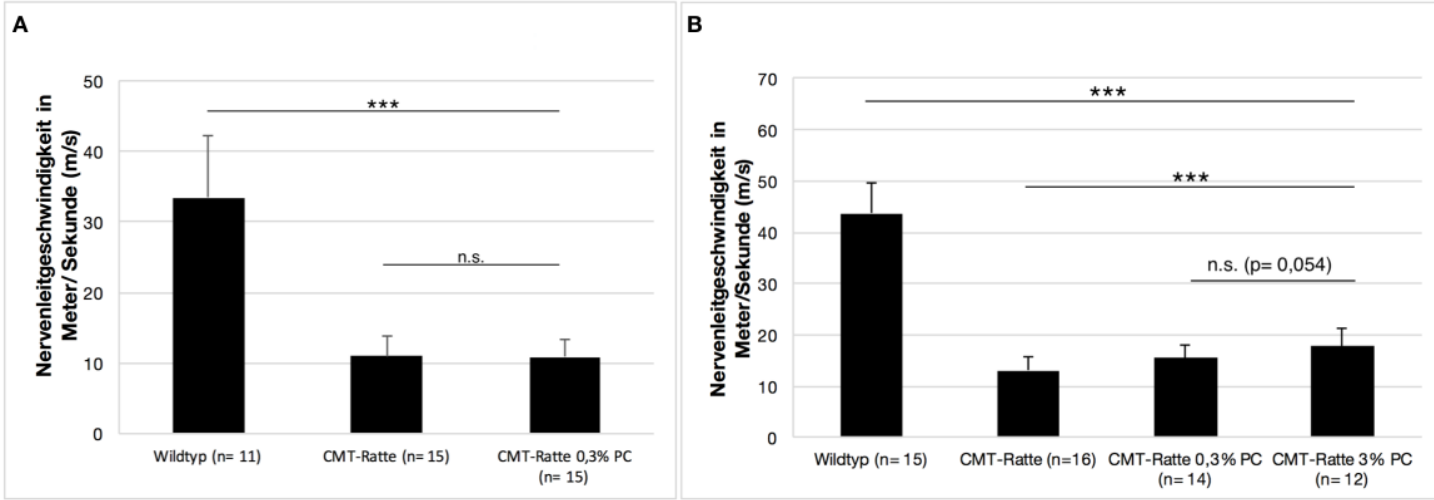

Abb. 10: Nervenleitgeschwindigkeit

A: Später Therapiebeginn; B: Früher Therapiebeginn; Wildtyp: Wildtyp-Ratten mit Spezialdiät für Ratten ohne Zusätze (Placebo) gefüttert; CMT-Ratte: CMT-Ratten mit Spezialdiät für Ratten ohne Zusätze (Placebo) gefüttert; CMT-Ratte 0,3 \% PC: CMT-Ratten mit Spezialdiät für Ratten und einem Zusatz von 0,3 Gew.-\% L- $\alpha-$ Phosphatidylcholin gefüttert; CMT-Ratte 3 \% PC: CMT-Ratten mit Spezialdiät für Ratten und einem Zusatz von 3,0 Gew.-\% L-a-Phosphatidylcholin gefüttert; Fehlerindikatoren: es wird die Standardabweichung angegeben; t-Test: *: p-Wert < 0,05; **: p-Wert < 0,01; ${ }^{* * *}$ : p-Wert < 0,001; ANOVA Dunnett-Test (2-seitig): *: p-Wert < 0,05; ${ }^{* *}$ : $p$-Wert $<0,01 ;{ }^{* * *}$ : p-Wert $<0,001$

\subsubsection{Später Therapiebeginn}

Das wie zuvor beschrieben supplementierte L-a-Phosphatidylcholin ist nicht in der Lage die Nervenleitgeschwindigkeit zum Ende der Therapiestudie (Alter der Versuchstiere: 20 Wochen) zu verbessern. Eine Dosis von 0,3 Gew.-\% L$\alpha-P h o s p h a t i d y l c h o l i n$ führt zu einem nicht signifikanten $(p=0,88)$ statistischen Unterschied der Nervenleitgeschwindigkeit der therapierten CMT-Ratten im 
Vergleich zur Nervenleitgeschwindigkeit der mit einem Placebo behandelten CMT Ratten.

\subsubsection{Früher Therapiebeginn}

Das wie zuvor beschrieben supplementierte L- $\alpha$-Phosphatidylcholin ist in der Lage die Nervenleitgeschwindigkeit als Therapieerfolg zum Ende der Therapiestudie (Alter der Versuchstiere: 16 Wochen) zu verbessern. Eine Dosis von 3,0 Gew.-\% L-a-Phosphatidylcholin führt zu einer signifikanten Erhöhung $(p=0,006)$ der Nervenleitgeschwindigkeit der therapierten CMTRatten im Vergleich zur Nervenleitgeschwindigkeit der mit einem Placebo behandelten CMT-Ratten. Die Erhöhung der Nervenleitgeschwindigkeit bei einer Dosis von 0,3 Gew.-\% L- $\alpha$-Phosphatidylcholin verbleibt hingegen nicht signifikant $(p=0,203)$.

\subsubsection{Distale Ableitung der Muskelsummenaktionspotentiale}
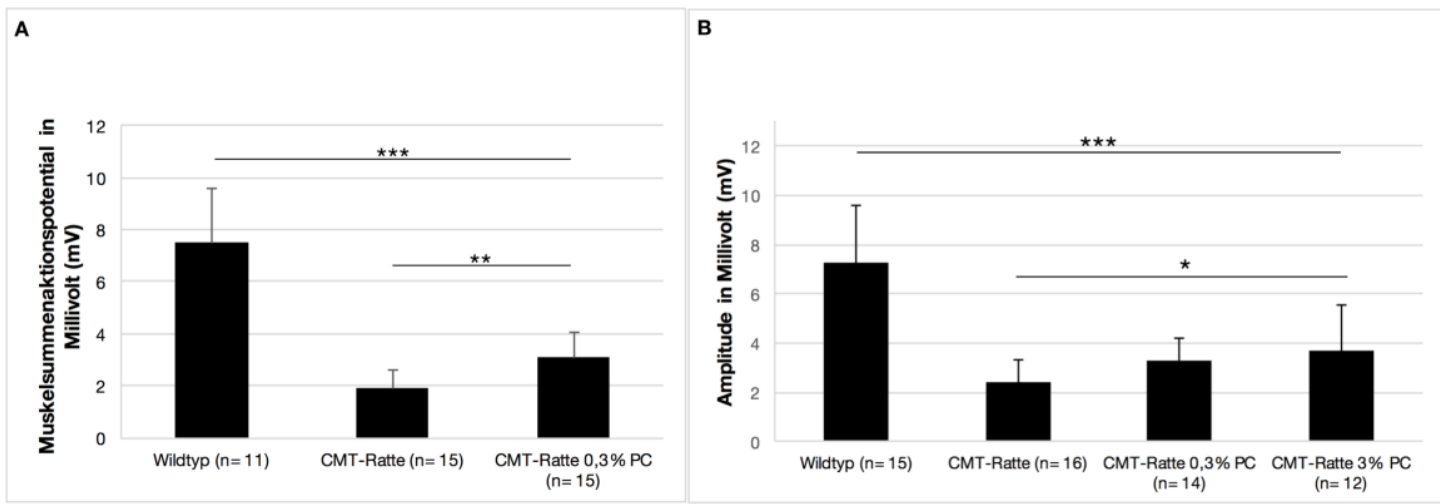

Abb. 11: Muskelsummenaktionspotential

A: Später Therapiebeginn; B: Früher Therapiebeginn; Wildtyp: Wildtyp-Ratten mit Spezialdiät für Ratten ohne Zusätze (Placebo) gefüttert; CMT-Ratte: CMT-Ratten mit Spezialdiät für Ratten ohne Zusätze (Placebo) gefüttert; CMT-Ratte 0,3 \% PC: CMT-Ratten mit Spezialdiät für Ratten und einem Zusatz von 0,3 Gew.-\% L- $\alpha-$ Phosphatidylcholin gefüttert; CMT-Ratte 3 \% PC: CMT-Ratten mit Spezialdiät für Ratten und einem Zusatz von 3,0 Gew.-\% L-a-Phosphatidylcholin gefüttert; Fehlerindikatoren: es wird die Standardabweichung angegeben; t-Test: *: p-Wert < 0,05; ${ }^{* *}$ : p-Wert < 0,01; ${ }^{* * *}$ : p-Wert < 0,001; ANOVA Dunnett-Test (2-seitig): *: p-Wert < 0,05; ${ }^{* *}$ : $p$-Wert $<0,01 ;{ }^{* * *}$ : $p$-Wert $<0,001$

\subsubsection{Später Therapiebeginn}

Das wie zuvor beschrieben supplementierte L- $\alpha$-Phosphatidylcholin ist in der Lage die distale Ableitung der Muskelsummenaktionspotentiale als 
Therapieerfolg zum Ende der Therapiestudie (Alter der Versuchstiere: 20 Wochen) zu verbessern. Eine Dosis von 0,3 Gew.-\% L-a-Phosphatidylcholin führt zu einer signifikanten Erhöhung $(p=0,001)$ der distalen Ableitung der Muskelsummenaktionspotentiale der therapierten CMT-Ratten im Vergleich zur distalen Ableitung der Muskelsummenaktionspotentiale der mit einem Placebo behandelten CMT Ratten.

\subsubsection{Früher Therapiebeginn}

Das wie zuvor beschrieben supplementierte L- $\alpha$-Phosphatidylcholin ist nicht in der Lage die distale Ableitung der Muskelsummenaktionspotentiale zum Ende der Therapiestudie (Alter der Versuchstiere: 16 Wochen) zu verbessern.

\subsubsection{Proximale Ableitung der Muskelsummenaktionspotentiale}
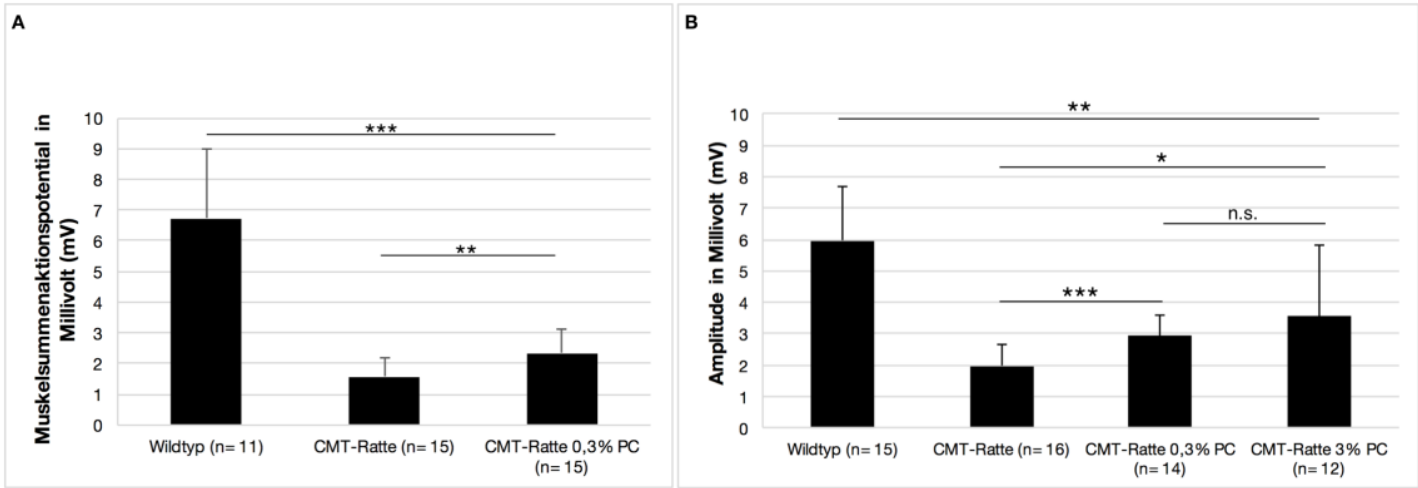

Abb. 12: Proximale Ableitung der Muskelsummenaktionspotentiale

A: Später Therapiebeginn; B: Früher Therapiebeginn; Wildtyp: Wildtyp-Ratten mit Spezialdiät für Ratten ohne Zusätze (Placebo) gefüttert; CMT-Ratte: CMT-Ratten mit Spezialdiät für Ratten ohne Zusätze (Placebo) gefüttert; CMT-Ratte 0,3 \% PC: CMT-Ratten mit Spezialdiät für Ratten und einem Zusatz von 0,3 Gew.-\% L- $\alpha$ Phosphatidylcholin gefüttert; CMT-Ratte 3 \% PC: CMT-Ratten mit Spezialdiät für Ratten und einem Zusatz von 3,0 Gew.-\% L-a-Phosphatidylcholin gefüttert; Fehlerindikatoren: es wird die Standardabweichung angegeben; t-Test: *: p-Wert < 0,05; **: p-Wert < 0,01; ${ }^{* * *}$ : p-Wert < 0,001; ANOVA Dunnett-Test (2-seitig): *: p-Wert < 0,05; ${ }^{\star *}:$ p-Wert $<0,01 ;{ }^{* * *}$ : p-Wert $<0,001$

\subsubsection{Später Therapiebeginn}

Das wie zuvor beschrieben supplementierte L- $\alpha$-Phosphatidylcholin ist in der Lage die proximale Ableitung der Muskelsummenaktionspotentiale als Therapieerfolg zum Ende der Therapiestudie (Alter der Versuchstiere: 20 Wochen) zu verbessern. Eine Dosis von 0,3 Gew.-\% L-a-Phosphatidylcholin 
führt zu einer signifikanten Erhöhung $(p=0,007)$ der proximalen Ableitung der Muskelsummenaktionspotentiale der therapierten CMT-Ratten im Vergleich zur proximalen Ableitung der Muskelsummenaktionspotentiale der mit einem Placebo behandelten CMT-Ratten.

\subsubsection{Früher Therapiebeginn}

Das wie zuvor beschrieben supplementierte L-a-Phosphatidylcholin ist in der Lage die proximale Ableitung der Muskelsummenaktionspotentiale als Therapieerfolg zum Ende der Therapiestudie (Alter der Versuchstiere: 16 Wochen) dosisabhängig zu verbessern. Eine Dosis von 3,0 Gew.-\% L-aPhosphatidylcholin führt zu einer signifikanten Erhöhung $(p=0,016)$ der proximalen Ableitung der Muskelsummenaktionspotentiale der therapierten CMT-Ratten im Vergleich zur proximalen Ableitung der Muskelsummenaktionspotentiale der mit einem Placebo behandelten CMT-Ratten. Die Erhöhung der Muskelsummenaktionspotentiale in der proximalen Ableitung bei einer Dosis von 0,3 Gew.-\% L-a-Phosphatidylcholin verbleibt hingegen nicht signifikant $(p=0,174)$.

\subsubsection{Sensible Aktionspotentiale}
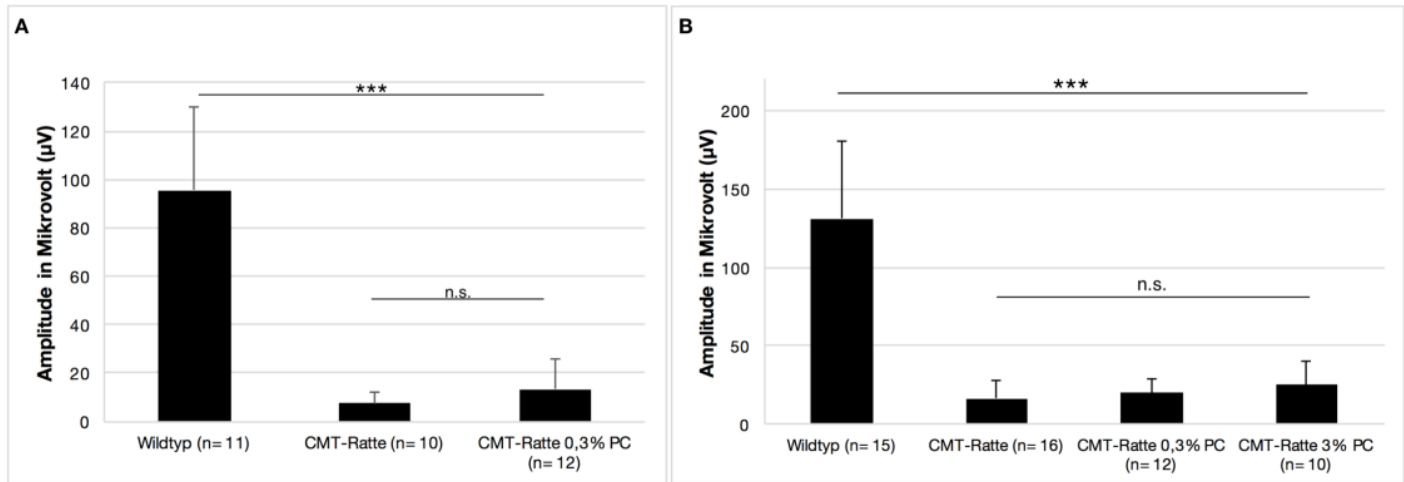

Abb. 13: Sensible Aktionspotentiale

A: Später Therapiebeginn; B: Früher Therapiebeginn; Wildtyp: Wildtyp-Ratten mit Spezialdiät für Ratten ohne Zusätze (Placebo) gefüttert; CMT-Ratte: CMT-Ratten mit Spezialdiät für Ratten ohne Zusätze (Placebo) gefüttert; CMT-Ratte $\mathbf{0 , 3} \%$ PC: CMT-Ratten mit Spezialdiät für Ratten und einem Zusatz von 0,3 Gew.-\% L- $\alpha$ Phosphatidylcholin gefüttert; CMT-Ratte 3 \% PC: CMT-Ratten mit Spezialdiät für Ratten und einem Zusatz von 3,0 Gew.-\% L-a-Phosphatidylcholin gefüttert; Fehlerindikatoren: es wird die Standardabweichung angegeben; t-Test: * p-Wert < 0,05; ${ }^{* *}$ : p-Wert < 0,01; ${ }^{* *}$ : p-Wert < 0,001; ANOVA Dunnett-Test (2-seitig): *: p-Wert < 0,05; ${ }^{* *}$ : p-Wert $<0,01 ;{ }^{* * *}$ : p-Wert $<0,001$ 


\section{Ergebnisse}

\subsubsection{Später Therapiebeginn}

Das wie zuvor beschrieben supplementierte L- $\alpha$-Phosphatidylcholin ist nicht in der Lage die sensiblen Aktionspotentiale zum Ende der Therapiestudie (Alter der Versuchstiere: 20 Wochen) zu verbessern. Eine Dosis von 0,3 Gew.-\% L$\alpha$-Phosphatidylcholin führt zu einem nicht signifikanten $(p=0,16)$ statistischen Unterschied der sensiblen Nervenleitgeschwindigkeit der therapierten CMTRatten im Vergleich zu den mit einem Placebo behandelten CMT-Ratten.

\subsubsection{Früher Therapiebeginn}

Das wie zuvor beschrieben supplementierte L- $\alpha$-Phosphatidylcholin ist nicht in der Lage die sensiblen Aktionspotentiale zum Ende der Therapiestudie (Alter der Versuchstiere: 16 Wochen) zu verbessern.

\subsubsection{Sensible Nervenleitgeschwindigkeit}
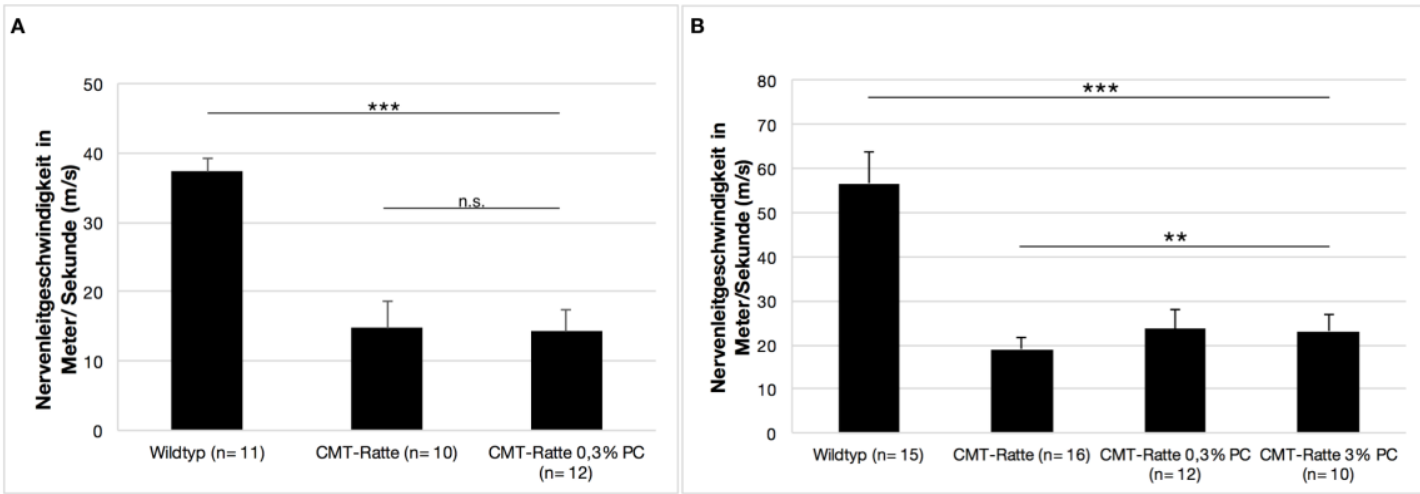

Abb. 14: Sensible Nervenleitgeschwindigkeit

A: Später Therapiebeginn; B: Früher Therapiebeginn; Wildtyp: Wildtyp-Ratten mit Spezialdiät für Ratten ohne Zusätze (Placebo) gefüttert; CMT-Ratte: CMT-Ratten mit Spezialdiät für Ratten ohne Zusätze (Placebo) gefüttert; CMT-Ratte 0,3 \% PC: CMT-Ratten mit Spezialdiät für Ratten und einem Zusatz von 0,3 Gew.-\% L-aPhosphatidylcholin gefüttert; CMT-Ratte 3 \% PC: CMT-Ratten mit Spezialdiät für Ratten und einem Zusatz von 3,0 Gew.-\% L-a-Phosphatidylcholin gefüttert; Fehlerindikatoren: es wird die Standardabweichung angegeben; t-Test: *: p-Wert < 0,05; **: p-Wert < 0,01; ***: p-Wert < 0,001; ANOVA Dunnett-Test (2-seitig): *: p-Wert < 0,05; ${ }^{* *}$ : $p$-Wert $<0,01 ;{ }^{* * *}$ : p-Wert $<0,001$

\subsubsection{Später Therapiebeginn}

Das wie zuvor beschrieben supplementierte L- $\alpha$-Phosphatidylcholin ist nicht in der Lage die sensible Nervenleitgeschwindigkeit zum Ende der Therapiestudie (Alter der Versuchstiere: 20 Wochen) zu verbessern. Eine Dosis von 0,3 Gew.- 
\% L-a-Phosphatidylcholin führt zu einem nicht signifikanten ( $p=0,77$ ) statistischen Unterschied der Nervenleitgeschwindigkeit der therapierten CMT-Ratten im Vergleich zu den mit einem Placebo behandelten CMT-Ratten.

\subsubsection{Früher Therapiebeginn}

Das wie zuvor beschrieben supplementierte L- $\alpha$-Phosphatidylcholin ist in der Lage die sensible Nervenleitgeschwindigkeit als Therapieerfolg zum Ende der Therapiestudie (Alter der Versuchstiere: 16 Wochen) dosisabhängig zu verbessern. Eine Dosis von 0,3 Gew.-\% L-a-Phosphatidylcholin führt zu einer signifikanten Erhöhung $(p=0,035)$ der sensiblen Nervenleitgeschwindigkeit der therapierten CMT-Ratten im Vergleich zu den mit einem Placebo behandelten CMT-Ratten. Die Erhöhung der sensiblen Nervenleitgeschwindigkeit bei einer Dosis von 3,0 Gew.-\% L-a-Phosphatidylcholin verbleibt hingegen nicht signifikant $(p=0,104)$. 
Ergebnisse

\subsection{Histopathologische Untersuchungen}

\subsubsection{Axonquantifizierung}
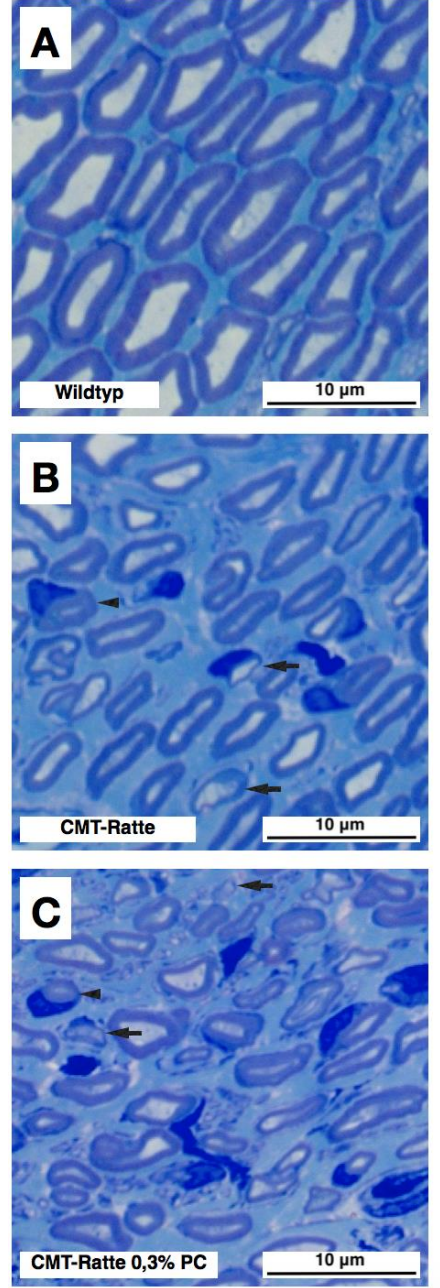

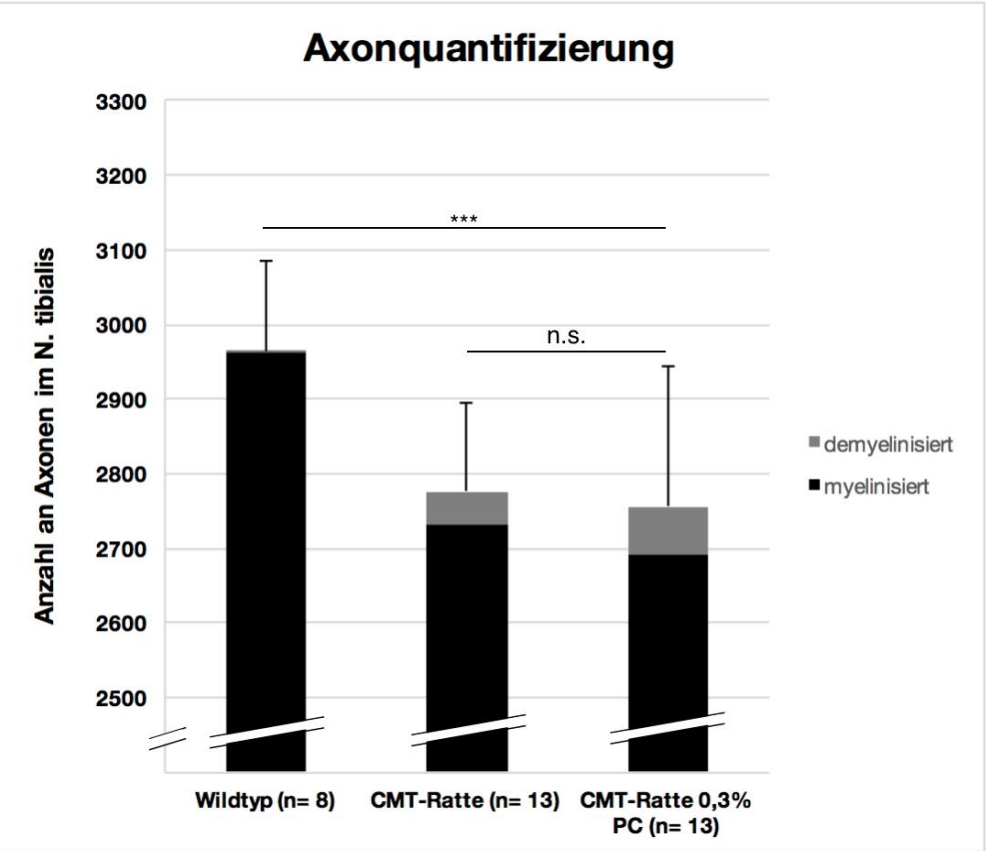

Wildtyp: Wildtyp-Ratten mit Spezialdiät für Ratten ohne Zusätze (Placebo) gefüttert; CMT-Ratte: CMT-Ratten mit Spezialdiät für Ratten ohne Zusätze (Placebo) gefüttert; CMT-Ratte 0,3\% PC: CMT-Ratten mit Spezialdiät für Ratten und einem Zusatz von 0,3Gew.-\% L-a-Phosphatidylcholin gefüttert; $\mathrm{n}$ : Anzahl der in die Statistik einbezogenen Versuchstiere

Pfeile: demyelinisierte Axone; Pfeilköpfe: hypermyelinisierte Axone

Fehlerindikatoren: es wird die Standardabweichung angegeben

t-Test: ${ }^{*}$ : p-Wert< 0,05; ${ }^{\star *}$ : p-Wert< 0,01; ${ }^{* * *}$ : p-Wert< 0,001

Abb. 15: Axonquantifizierung - später Therapiebeginn

\subsubsection{Später Therapiebeginn}

Das wie zuvor beschrieben supplementierte L-a-Phosphatidylcholin ist nicht in der Lage die Anzahl an Axonen zum Ende der Therapiestudie (Alter der Versuchstiere: 20 Wochen) zu erhöhen. Eine Dosis von 0,3 Gew.-\% L- $\alpha-$ Phosphatidylcholin führt zu einem nicht signifikanten $(p=0,5)$ statistischen Unterschied der Nervenleitgeschwindigkeit der therapierten CMT-Ratten im Vergleich zu den mit einem Placebo behandelten CMT-Ratten. 


\section{Ergebnisse}
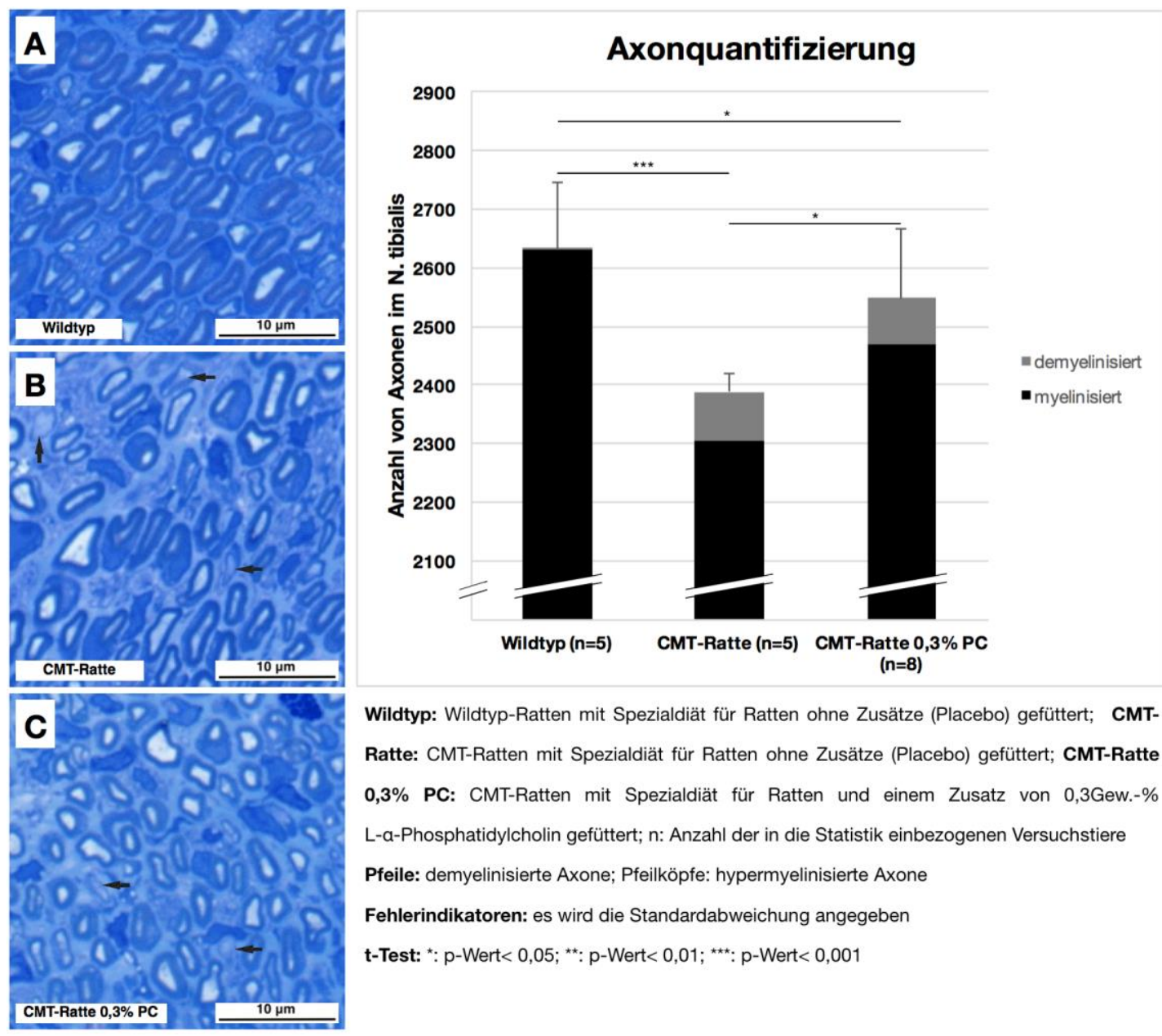

Wildtyp: Wildtyp-Ratten mit Spezialdiät für Ratten ohne Zusätze (Placebo) gefüttert; CMTRatte: CMT-Ratten mit Spezialdiät für Ratten ohne Zusätze (Placebo) gefüttert; CMT-Ratte 0,3\% PC: CMT-Ratten mit Spezialdiät für Ratten und einem Zusatz von 0,3Gew.-\% L-a-Phosphatidylcholin gefüttert; $n$ : Anzahl der in die Statistik einbezogenen Versuchstiere Pfeile: demyelinisierte Axone; Pfeilköpfe: hypermyelinisierte Axone

Fehlerindikatoren: es wird die Standardabweichung angegeben

t-Test: ${ }^{\star}:$ p-Wert< 0,05; ${ }^{\star \star}:$ p-Wert< 0,$01 ;{ }^{\star \star \star}:$ p-Wert $<0,001$

Abb. 16: Axonquantifizierung - früher Therapiebeginn (Kurzzeitstudie)

\subsubsection{Früher Therapiebeginn (Kurzzeitstudie)}

Das wie zuvor beschrieben supplementierte L- $\alpha$-Phosphatidylcholin ist in der Lage die Axonanzahl des $N$. tibialis als Therapieerfolg zum Ende der Therapiestudie (Alter der Versuchstiere: 16 Wochen) dosisabhängig zu verbessern. Eine Dosis von 0,3 Gew.-\% L-a-Phosphatidylcholin führt zu einer signifikanten Erhöhung $(p=0,012)$ der Axonanzahl des $N$. tibialis der therapierten CMT-Ratten im Vergleich zu den mit einem Placebo behandelten CMT-Ratten. 


\section{Ergebnisse}

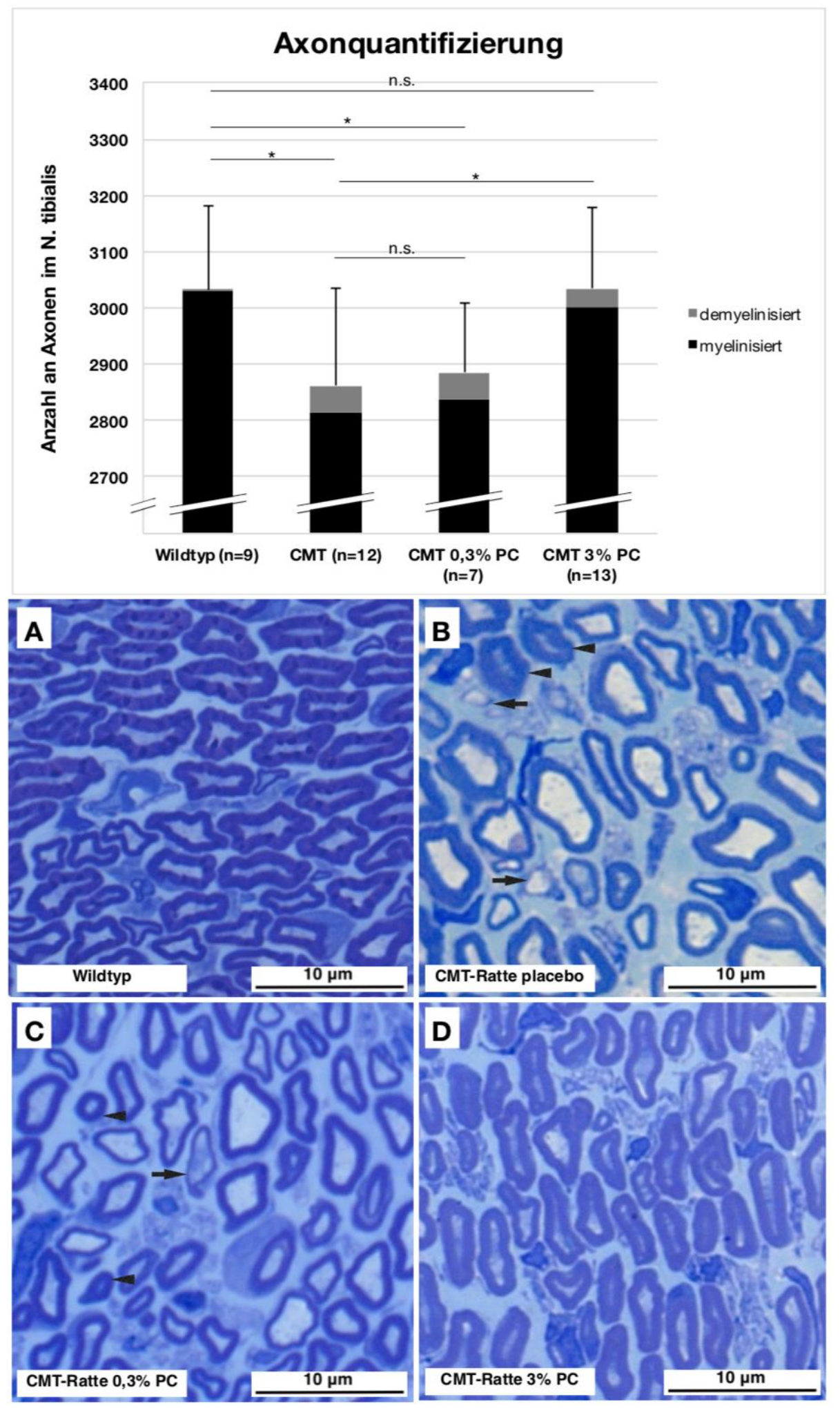

Abb. 17: Axonquantifizierung - früher Therapiebeginn

Wildtyp: Wildtyp-Ratten mit Spezialdiät für Ratten ohne Zusätze (Placebo) gefüttert; CMT: CMT-Ratten mit Spezialdiät für Ratten ohne Zusätze (Placebo) gefüttert; CMT 0,3 \% PC: CMT-Ratten mit Spezialdiät für Ratten und einem Zusatz von 0,3 Gew.-\% L- $\alpha$-Phosphatidylcholin gefüttert; CMT 3 \% PC: CMT-Ratten mit Spezialdiät für Ratten und einem Zusatz von 3,0 Gew.-\% L-a-Phosphatidylcholin gefüttert; Fehlerindikatoren: es wird die Standardabweichung angegeben; t-Test: ${ }^{*}$ : $\mathrm{p}$-Wert $<0,05$; ${ }^{* *}$ : $\mathrm{p}-$ Wert $<0,01 ;{ }^{* * *}$ : $\mathrm{p}$-Wert $<0,001$; ANOVA DunnettTest (2-seitig): *: p-Wert $<0,05 ;{ }^{* *}$ : p-Wert $<0,01 ;{ }^{* * *}$ : p-Wert $<0,001$ 


\section{Ergebnisse}

\subsubsection{Früher Therapiebeginn}

Das wie zuvor beschrieben supplementierte L- $\alpha$-Phosphatidylcholin ist in der Lage die Axonanzahl des $N$. tibialis als Therapieerfolg zum Ende der Therapiestudie (Alter der Versuchstiere: 16 Wochen) dosisabhängig zu erhöhen. Eine Dosis von 3,0 Gew.-\% L-a-Phosphatidylcholin führt zu einer signifikanten Erhöhung $(p=0,034)$ der Axonanzahl des $N$. tibialis der therapierten CMT-Ratten im Vergleich zu den mit einem Placebo behandelten CMT-Ratten, wobei die Axonanzahl des N. tibialis der therapierten CMTRatten das Niveau $(p=1)$ der Wildtyp-Ratten erreicht. Die Erhöhung der Axonanzahl des $N$. tibialis bei einer Dosis von 0,3 Gew.-\% L-aPhosphatidylcholin verbleibt hingegen nicht signifikant $(p=0,98)$.

\subsubsection{G-ratio}

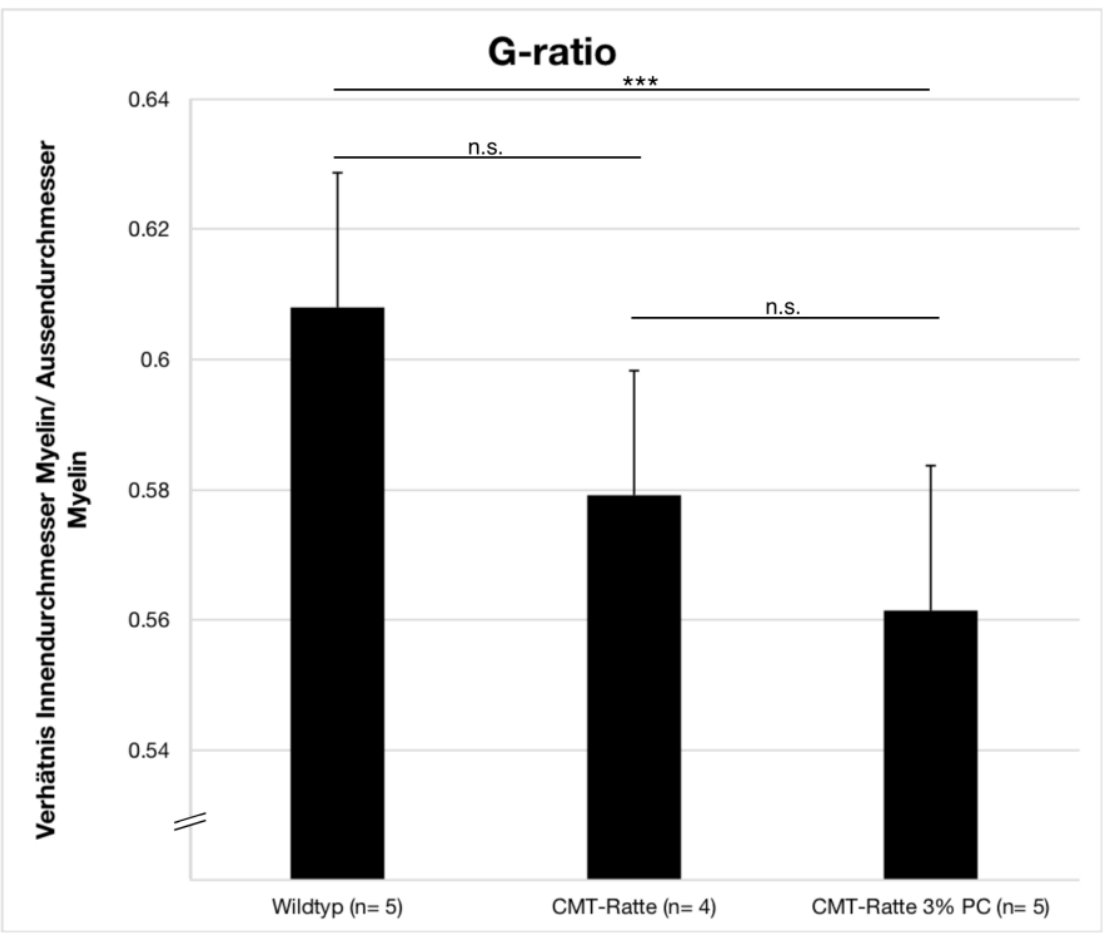

Abb. 18: G-ratio

Wildtyp: Wildtyp-Ratten mit Spezialdiät für Ratten ohne Zusätze (Placebo) gefüttert; CMT-Ratte: CMT-Ratten mit Spezialdiät für Ratten ohne Zusätze (Placebo) gefüttert; CMT-Ratte 3 \% PC: CMT-Ratten mit Spezialdiät für Ratten und einem Zusatz von 3,0 Gew.-\% L-a-Phosphatidylcholin gefüttert; Fehlerindikatoren: es wird die Standardabweichung angegeben; t-Test: ${ }^{*}$ : -Wert $<0,05 ;{ }^{* *}$ : p-Wert $<0,01 ;{ }^{* *}$ : p-Wert $<0,001$ 


\section{Ergebnisse}

Das wie zuvor beschrieben supplementierte L-a-Phosphatidylcholin ist nicht in der Lage das G-ratio zum Ende der Therapiestudie (Alter der Versuchstiere: 16 Wochen) auf das Niveau der Wildtyp-Ratten zu heben. Das G-ratio von CMT-Ratten, welche mit 3 Gew.-\% L-a-Phosphatidylcholin behandelt wurden, ist signifikant $(p=0,009)$ kleiner als das von Wildtyp-Ratten. 


\section{Diskussion}

\subsection{Das Ausmaß des Therapieerfolges ist vom Zeitpunkt der initialen Verabreichung und der verabreichten Dosis des L- $\alpha-$ Phosphatidylcholin abhängig}

Die experimentellen Therapiestudien der hier vorgelegten Arbeit zeigen allesamt einen Therapieerfolg dessen Ausmaß vom Zeitpunkt der initialen Verabreichung und der verabreichten Dosis des L-a-Phosphatidylcholin abhängig ist.

Die Studie mit spätem Therapiebeginn beinhaltete einen Verabreichungsbeginn am 18. Postnataltag der Versuchstiere und eine verabreichte Dosis von 0,3 Gew.-\% L-a-Phosphatidylcholin. Innerhalb dieser Studie entfiel der Therapieerfolg fast ausschließlich auf die Verbesserung klinischer Erkrankungsparameter. Im Bereich der elektrophysiologischen Parameter verbesserten sich lediglich die distalen und proximalen CMAP, wobei ein positiver Effekt auf deren histologisches Korrelat, die Axonanzahl in peripheren Nerven (repräsentiert durch die Anzahl an Axonen im N. tibialis) ausblieb. Diese Ergebnisse lassen vor allem darauf schließen, dass all jene Axone peripherer Nerven von einer Therapie mit L-a-Phosphatidylcholin profitieren, welche nicht im Rahmen früher postnataler Pathomechanismen verloren gegangen sind. Zu diesen Pathomechanismen, die typisch für die CMT1A bei der CMT-Ratte sind, zählen die sekundäre Demyelinisierung und die anschließende Axondegeneration. Im Rahmen einer aktuellen Arbeit konnte gezeigt werden, dass wesentliche pathomechanische Ereignisse, welche die o. g. Pathologie bedingen, bereits innerhalb des sechsten bis 18 . Postnataltages stattfinden (Fledrich et al. 2014).

Um das Ausmaß des Therapieerfolges auszuweiten, wurde in Anbetracht der o. g. Beobachtungen und Überlegungen ein früherer Behandlungsbeginn für zukünftige Therapiestudien als zielführend festgelegt. 
Zur zeitlich effizienten Überprüfung des Therapieeffekts eines frühen Behandlungsbeginns (23. Embryonaltag) wurde eine Studie mit deutlich verkürzter Behandlungsdauer (bis zum 18. Postnataltag) und einer kleineren Anzahl an Tieren gewählt. Vorrangiges Ziel dieser Studie war es, den Effekt einer frühen Therapie mit L- $\alpha$-Phosphatidylcholin auf die o. g. frühen postnatalen Pathomechanismen bei der CMT-Ratte zu überprüfen. Dementsprechend stand die histopathologische Untersuchung im Sinne einer Axonquantifizierung des $N$. tibialis im Vordergrund der Betrachtungen. Den Ergebnissen des Griffstärketests kann aufgrund des nicht vorhandenen Trainings der Versuchstiere keine allzu starke Aussagekraft eingeräumt werden und elektrophysiologische Untersuchungen hätten bei Tieren dieses Alters keine repräsentativen Daten ergeben. Ein früher Behandlungsbeginn mit L- $\alpha$-Phosphatidylcholin vermag dem Axonverlust in peripheren Nerven in der Tat signifikant entgegenzuwirken, was einen Einfluss von L- $\alpha-$ Phosphatidylcholin auf frühe postnatale Pathomechanismen der CMT1A nahelegt.

In Anlehnung an die Ergebnisse aus der Kurzzeitstudie mit frühem Behandlungsbeginn wurde eine zweite Studie mit frühem Behandlungsbeginn durchgeführt. Hierbei wurde der Behandlungsbeginn auf den zweiten Postnataltag gelegt, die Behandlungsdauer erstreckte sich bis zur 16. Lebenswoche und es wurden zwei verschiedene Dosen L-aPhosphatidylcholin (0,3 und 3 Gew.-\%) verabreicht. Der zweite Postnataltag wurde als Behandlungsbeginn angesetzt, da nur so eine homogene Gruppengröße gemäß den Genotypen, also mit zuvor durchgeführter Genotypisierung, umgesetzt werden konnte. Im Rahmen dieser Studie wurden klinische, elektrophysiologische und histopathologische Untersuchungen durchgeführt. Die klinischen Untersuchungen zeigen beim Griffstärketest sowohl für die Vorder- als auch die Hinterläufe einen dosisabhängigen Effekt der Verabreichung von L-a-Phosphatidylcholin. Während die Gruppe der mit einem Zusatz von 0,3 Gew.-\% L- $\alpha$-Phosphatidylcholin therapierten CMT- 
Ratten bei der Griffstärke weder für die Vorder- noch die Hinterläufe signifikant höhere Werte als die nicht therapierte CMT-Ratte aufwiesen, so ist dies bei der Gruppe der mit einem Zusatz von 3 Gew.-\% L-a-Phosphatidylcholin therapierten CMT-Ratten der Fall. Sowohl bei einer Therapie mit 0,3 Gew.-\% als auch 3 Gew.-\% L- $\alpha$-Phosphatidylcholin kann eine Normalisierung des Körpergewichtes auf das Niveau von Wildtyp-Ratten erreicht werden, sodass sich zusammenfassend für alle klinischen Untersuchungen ein umfassender Therapieerfolg für die Therapie mit 3 Gew.-\% L-a-Phosphatidylcholin beobachten lässt, der für die Therapie mit 0,3 Gew.-\% L-a-Phosphatidylcholin lediglich auf das Körpergewicht begrenzt bleibt.

Im Bereich der elektrophysiologischen Untersuchungen lassen sich weder für eine Dosis von 0,3 Gew.-\% noch 3 Gew.-\% L-a-Phosphatidylcholin durchgehende Therapieerfolge registrieren. Es bleibt allerdings zu bemerken, dass für die Dosis von 3 Gew.-\% L- $\alpha$-Phosphatidylcholin im Bereich der Nervenleitgeschwindigkeit und der Muskelsummenaktionspotentiale (proximale Ableitung), zweier sehr wichtiger elektrophysiologischer Parameter für die Beurteilung der CMT, solide Therapieerfolge zu verzeichnen sind. Für die Dosis von 0,3 Gew.-\% L-a-Phosphatidylcholin kann lediglich im Bereich der sensiblen Nervenleitgeschwindigkeit ein signifikant erhöhter Wert gegenüber der CMT-Ratte ohne Therapie beobachtet werden.

Im Bereich der histopathologischen Untersuchung mittels der Axonquantifizierung konnte jedoch nur für die mit 3 Gew.-\% L-a-Phosphatidylcholin therapierte Gruppe eine signifikant erhöhte Anzahl an Axonen gegenüber der CMT-Ratte analysiert werden, wobei sogar das Niveau von Wildtyp-Ratten erreicht wird.

Eine Zusammenschau der Ergebnisse aller o. g. Studien liefert folgende Interpretationen hinsichtlich der Rahmenbedingungen einer Therapie mit L- $\alpha$ Phosphatidylcholin.

Hinsichtlich der initialen Verabreichung von L-a-Phosphatidylcholin ist eine möglichst frühzeitige postnatale Verabreichung anzustreben. Die Ergebnisse 
der klinischen Untersuchungen bleiben für die mit 0,3 Gew.-\% L-aPhosphatidylcholin therapierten Gruppen gegenüber der nicht therapierten CMT-Ratte über die Studien hinweg inkonstant. Auch kann bei einer früh postnatalen Verabreichung dieser Dosis für fast alle elektrophysiologischen Parameter und die histopathologische Untersuchung kein Therapieerfolg observiert werden. Für einen umfassenden Therapieerfolg, der klinische, histopathologische und z. T. elektrophysiologische Messwerte einschließt, sollte eine Dosis von 3 Gew.-\% L- $\alpha$-Phosphatidylcholin früh postnatal verabreicht werden, da unter diesen Rahmenbedingungen Krankheitsparameter in allen drei o. g. Untersuchungsbereichen verbessert werden. Zudem kann bei dieser Dosis ein kontinuierlicher Therapieerfolg bis zu Ende der Studie beobachtet werden, während die frühe postnatale Verabreichung von 0,3 Gew.-\% L-a-Phosphatidylcholin vorwiegend auf die ersten Lebenswochen begrenzt zu sein scheint, was ein Vergleich der Ergebnisse aus der Kurzzeitstudie und der Langzeitstudie mit frühem Behandlungsbeginn zeigt. Inwiefern bereits eine auf die ersten 18 Postnataltage begrenzte Applikation von 3 Gew.-\% L- $\alpha$-Phosphatidylcholin einen langfristigen Therapieerfolg liefert, bleibt zu untersuchen.

\subsection{Hypothetische Überlegungen zum molekularen Wirkungsmechanismus von L- $\alpha$-Phosphatidylcholin}

Die Ätiologie der CMT1A begründet sich in einer intrachromosomalen Duplikation des Chromosomenabschnitts 17p11.2-12, auf welcher das Gen für das PMP22 lokalisiert ist. Die damit verbundene pathologische Gendosiserhöhung des PMP22 führt zu Schwannzell-spezifischen Fehlfunktionen. Der Pathomechanismus der CMT1A ist zum derzeitigen Zeitpunkt nicht vollständig aufgeklärt. In-vitro-Experimente mit Schwannzellen, welche PMP22 überexprimieren, haben zu der Beobachtung geführt, dass sich das überschüssige PMP22 im Cytosol der Schwannzellen in Form von 
Aggresomen ansammelt (Notterpek et al. 1999). Die Fragegestellung, inwiefern dieses Phänomen in vivo in Tiermodellen und Patienten mit CMT1A auftritt oder hier einen Einfluss auf die Pathologie hat, bleibt zu untersuchen. Nichtsdestotrotz konnten bereits positive Therapieeffekte hinsichtlich des Einsatzes eines Progesteron-Antagonisten (Onapristone), welcher indirekt die Expression des PMP22 vermindert, erzielt werden (Sereda et al. 2003; Meyer zu Hörste et al. 2007). Ein kausaler Therapieansatz, also solch einer, der eine Verminderung der PMP22-Expression vorsieht, stellt eine Möglichkeit der Therapie der CMT1A dar.

Neben pathomechanischen Aspekten der Schwannzellfunktionen innerhalb der CMT1A, welche in direktem Zusammenhang mit der Gendosiserhöhung des PMP22 gebracht werden können, kommt der Entgleisung bestimmter Stoffwechselwege innerhalb dieser Erkrankung eine hervorgehobene Bedeutsamkeit zu. In diesem Zusammenhang ist besonders die Synthese von Fettsäuren und daraus hervorgehenden Lipiden, welche für die Myelinisierung und somit für die elektrophysiologische Isolation der Axone peripherer Nerven essentiell sind, erwähnenswert (Simons und Trotter 2007). Eine Dysregulation der Stoffwechselwege, welche direkt oder indirekt für die Synthese bestimmter Lipide als Bestandteile der Myelinscheide von Axonen peripherer Nerven verantwortlich sind, konnte bereits mit der Verschlechterung neurophysiologischer Parameter wie der NLG in Verbindung gebracht werden (Bosio et al. 1996; Garbay et al. 2000).

Für die CMT-Ratte konnten im Rahmen einer Arbeit zur Identifikation von Biomarkern, dysregulierte Stoffwechselwege einiger Lipide, welche für die Zusammensetzung der Myelinscheiden der Axone peripherer Nerven bedeutsam sind, ermittelt werden (Fledrich et al. 2012). Aus dem Stand der Technik ist bekannt, dass diese Stoffwechselwege in entscheidenden Phasen der Myelinisierung besonders hoch frequentiert sind, weswegen sie offensichtlich ein wichtiger Teil dieses Prozesses sind (Verheijen et al. 2003). 
Weiterhin lässt sich hieraus und aus der Tatsache des hohen Lipidgehaltes der Myelinscheiden (Lazzarini et al. 2004) schlußfolgern, dass eine Dysregulation des Lipidstoffwechsels eine wesentliche Bedeutung für die pathologischen Veränderungen der Myelinisierung peripherer Axone bei der CMT1A haben könnte.

Ein eindrucksvolles Beispiel für den Einfluss dysregulierter Stoffwechselwege der Lipidsynthese stellt die Inaktivierung der Squalensynthase dar. Dieses Enzym katalysiert einen Teilschritt der Cholesterinsynthese und seine Inaktivierung führt zu einer Beeinträchtigung der Myelinisierung des Zentralnervensystems (Saher et al. 2005).

Neben ihrer Bedeutung als struktureller Bestandteil des Myelins, stellen die Phospholipide eine Quelle für Fettsäuren dar und sind Ausgangsstoffe bioaktiver Lipide, wie beispielsweise der Arachidonsäure (Kent und Carman 1999). Arachidonsäure konnte wiederum bereits in Zusammenhang mit der Myelinisierung peripherer Axone gebracht werden (Yao 1982; Liang et al. 2007).

Die Supplementierung des Substanzgemisches mit hohen Anteilen an L- $\alpha-$ Phosphatidylcholin aber auch anderer Phospholipide (s. o.) führt zu einer Umgehung der dysregulierten Fettsäurestoffwechselwege, wie die Ergebnisse weiterführender Experimente, die auf den Beobachtungen der hier vorgelegten Arbeit basieren, zeigen (Fledrich et al. 2018).

Phospholipide stellen zusammen mit Cholesterin den prozentual größten Anteil an Lipiden innerhalb der Myelinscheiden peripherer Axone dar (O'Brien et al. 1967). Ein veränderter Lipidmetabolismus aufgrund dysregulierter Stoffwechselwege führt zu einer veränderten Komposition der Lipide und entsprechenden Fettsäuren innerhalb der Myelinscheiden (Fledrich et al. 2018). Eine solche Veränderung der Lipidzusammensetzung des Myelins peripherer Axone konnte bereits bei Ratten mit einer experimentell induzierten diabetischen Polyneuropathie beobachtet und in direktem Zusammenhang mit 
pathologisch veränderten elektrophysiologischen Parametern, wie der Nervenleitgeschwindigkeit, gebracht werden (Cermenati et al. 2012). Untersuchungen der Lipidzusammensetzung des Myelins der CMT-Ratte zeigten, dass die Anzahl von Fettsäuren mit einer Kettenlänge von 18 Kohlenstoffatomen reduziert ist und durch die Supplementierung des Substanzgemisches mit hohen Anteilen an L- $\alpha$-Phosphatidylcholin aber auch anderen Phospholipiden (s. o.) wieder erhöht werden kann (Fledrich et al. 2018). Erwähnenswert ist hierbei, dass das o. g. Substanzgemisch zu $85 \%$ aus Fettsäuren mit einer Kettenlänge von 18 Kohlenstoffatomen besteht. Auch gelang mittels intravenöser Injektion speziell markierten Phosphatidylcholins und anschließender fluoreszenzmikroskopischer Untersuchung des $N$. ischiadicus der Nachweis, dass die verabreichten Lipide in die Myelinscheiden eingebaut werden und somit eine Rolle bei der Myelinisierung spielen (Fledrich et al. 2018).

Im Rahmen der experimentellen Therapiestudie an CMT-Ratten mit frühem Behandlungsbeginn, wie sie Gegenstand der hier vorgelegten Arbeit ist, konnte eine signifikante Erhöhung der Nervenleitgeschwindigkeit bei CMTRatten, welche mit L-a-Phosphatidylcholin gefüttert wurden, gegenüber solchen CMT Ratten, welche mit einem Standardfutter gefüttert wurden, festgestellt werden. In diesem Zusammenhang ist die Tatsache, dass die Nervenleitgeschwindigkeit ein elektrophysiologisches Korrelat zur Myelinisierung von Axonen darstellt, besonders erwähnenswert. Auch die elektrophysiologischen Untersuchungen bestätigen somit den positiven Einfluss, den die Verabreichung des Substanzgemisches mit hohen Anteilen an L- $\alpha-$ Phosphatidylcholin auf die Myelinisierung bei der CMT-Ratte hat. Infolge der angehobenen Nervenleitgeschwindigkeit verbessern sich indirekt Parameter wie die Axonanzahl in peripheren Nerven und somit elektrophysiologische Parameter wie die CMAP und die Griffstärke bei den therapierten CMT-Ratten der experimentellen Therapiestudie. 
Aus hypothetischer Sicht bietet sich eine weitere Überlegung bezüglich des Wirkungsmechanismus der Komponenten des o. g. Substanzgemisches an. Im Rahmen der Forschung zur Pelizaeus-Merzbacher-Krankheit, konnte festgestellt werden, dass sich das überexprimierte Proteolipid-Protein (PLP), ein Myelinprotein, zusammen mit Cholesterin in Endosomen und Lysosomen ansammelt (Simons et al. 2002). Die Verfütterung eines Futters, welches mit Cholesterin angereichert wurde, ist in der Lage diverse elektrophysiologische und phänotypische Parameter bei transgenen Mäusen, die gemäß der humanen Pelizaeus-Merzbacher-Krankheit das Plp1 Gen überexprimieren, zu verbessern (Saher et al. 2012). Als Ursache für den Therapieerfolg wird hierbei die Bindung des PLP an exogenes Cholesterin, der anschließende Transport zur Myelinscheide und die dortige Verankerung diskutiert, wobei das endogene Cholesterin hierfür nicht in ausreichenden Mengen vorzuliegen scheint.

Auch für die Phospholipide, die ebenso wie Cholesterin ein wichtiger Bestandteil der Myelinscheiden sind, ist bekannt, dass sie in Membranen an Proteine gebunden vorliegen können. Eine Bindung des überschüssigen PMP22, der Pathologie der CMT1A entsprechend, an exogene Phospholipide, der anschließende Transport zur Myelinscheide und die dortige Verankerung könnten den zuvor beschriebenen Beobachtungen entsprechen und somit den im Rahmen dieser Arbeit festgestellten Therapieerfolg in der Behandlung der CMT-Ratten begründen. 


\section{Zusammenfassung}

\section{Zusammenfassung}

Innerhalb der heriditären Neuropathien tritt die CMT mit einer Prävalenz von ca. 4 pro 10.000 am häufigsten auf, wobei ihr größter Subtyp die CMT1A ist, welche zu den demyelinisierenden Polyneuropathien zählt. In Anbetracht der vergleichsweise hohen Prävalenz der CMT1A und der mitunter drastischen motorischen Behinderungen der betroffenen Patienten verbleibt eine medikamentöse Therapie der Erkrankung ein hervorgehobenes Ziel in der auf dieses Gebiet bezogenen Forschung.

Für die experimentelle Erprobung eines Substanzgemisches mit einem hohen Anteil an L- $\alpha$-Phosphatidylcholin für die medikamentöse Therapie der CMT1A wurden Therapiestudien an der CMT-Ratte durchgeführt. Die CMT-Ratte bildet die humane CMT1A sowohl auf histopathologischer, neurophysiologischer als auch phänotypischer Ebene besonders suffizient nach. Die Symptomatik der CMT1A im Bereich dieser drei Ebenen begründet sich durch eine Demyelinisierung peripherer Axone, einem hierdurch hervorgerufenen sekundären axonalen Verlust, welcher eine verminderte Innervation nachgeschalteter Muskulatur und schließlich eine Muskelatrophie insbesondere der distalen Extremitäten bedingt.

Im Rahmen der hier vorgelegten Arbeit wurden verschiedene experimentelle Therapiestudien durchgeführt, deren Zielsetzung die Entwicklung eines wirksamen Therapievorgehens mittels der oralen Applikation von L-a-Phosphatidylcholin war. Eine früh postnatale Applikation eines 3 Gew.-\% L-a-Phosphatidylcholin Futterzusatzes lieferte hierbei Ergebnisse im Sinne eines Therapieerfolges sowohl auf histologischer, neurophysiologischer als auch phänotypischer Ebene. Neben den Therapieerfolgen sprechen insbesondere die technisch einfache Applikationsform und das Ausbleiben von Nebenwirkungen für die hier vorgestellte Therapiestrategie. Wenngleich der molekulare Wirkungsmechanismus von L- $\alpha$-Phosphatidylcholin nur teilweise untersucht ist, so liefert diese Arbeit doch einen wichtigen Beitrag für die Entwicklung einer medikamentösen Therapie der CMT1A. 


\section{Literaturverzeichnis}

Attarian S, Vallat JM, Magy L, Funalot B, Gonnaud PM, Lacour A, Péréon Y, Dubourg O, Pouget J, Micallef J et al. (2014): An exploratory randomised double-blind and placebo-controlled phase 2 study of a combination of baclofen, naltrexone and sorbitol (PXT3003) in patients with Charcot-MarieTooth disease type 1A. Orphanet J Rare Dis $\underline{9}, 199$

Bosio A, Binczek E, Stoffel W (1996): Functional breakdown of the lipid bilayer of the myelin membrane in central and peripheral nervous system by disrupted galactocerebroside synthesis. Proc Natl Acad Sci U S A $\underline{93}, 13280-13285$

Cermenati G, Abbiati F, Cermenati S, Brioschi E, Volonterio A, Cavaletti G, Saez E, De Fabiani E, Crestani M, Garcia-Segura LM et al. (2012): Diabetesinduced myelin abnormalities are associated with an altered lipid pattern: protective effects of LXR activation. J Lipid Res $\underline{53}, 300-310$

Chapman AL, Bennett EJ, Ramesh TM, De Vos KJ, Grierson AJ (2013): Axonal transport defects in a Mitofusin 2 loss of function model of charcotmarie-tooth disease in zebrafish. PLoS One $\underline{8}$, e67276

Chumakov I, Milet A, Cholet N, Primas G, Boucard A, Pereira Y, Graudens E, Mandel J, Laffaire J, Foucquier J et al. (2014): Polytherapy with a combination of three repurposed drugs (PXT3003) down-regulates Pmp22 over-expression and improves myelination, axonal and functional parameters in models of CMT1A neuropathy. Orphanet J Rare Dis $\underline{9}, 201$ 
d'Ydewalle C, Krishnan J, Chiheb DM, Van Damme P, Irobi J, Kozikowski AP, Vanden Berghe P, Timmerman V, Robberecht W, Van Den Bosch L (2011): HDAC6 inhibitors reverse axonal loss in a mouse model of mutant HSPB1induced Charcot-Marie-Tooth disease. Nat Med 17, 968-974

Fledrich R, Schlotter-Weigel B, Schnizer TJ, Wichert SP, Stassart RM, Zu Hörste GM, Klink A, Weiss BG, Haag U, Walter MC et al. (2012): A rat model of Charcot-Marie-Tooth disease $1 \mathrm{~A}$ recapitulates disease variability and supplies biomarkers of axonal loss in patients. Brain $\underline{135}, 72-87$

Fledrich R, Stassart RM, Klink A, Rasch LM, Prukop T, Haag L, Czesnik D, Kungl T, Abdelaal TA, Keric $\mathrm{N}$ et al. (2014): Soluble neuregulin-1 modulates disease pathogenesis in rodent models of Charcot-Marie-Tooth disease $1 \mathrm{~A}$. Nat Med 므, 1055-1061

Fledrich R, Abdelaal T, Rasch L, Bansal V, Schütza V, Brügger B, Lüchtenborg C, Prukop T, Stenzel J, Rahman RU et al. (2018): Targeting myelin lipid metabolism as a potential therapeutic strategy in a model of CMT1A neuropathy. Nat Commun $\underline{9}, 3025$

Garbay B, Heape AM, Sargueil F, Cassagne C (2000): Myelin synthesis in the peripheral nervous system. Prog Neurobiol 61, 267-304

Huxley C, Passage E, Manson A, Putzu G, Figarella-Branger D, Pellissier JF, Fontes M (1996): Construction of a mouse model of Charcot-Marie-Tooth disease type $1 \mathrm{~A}$ by pronuclear injection of human YAC DNA. Hum Mol Genet $\underline{5}, 563-569$ 
Janssens K, Goethals S, Atkinson D, Ermanoska B, Fransen E, Jordanova A, Auer-Grumbach M, Asselbergh B, Timmerman V (2014): Human Rab7 mutation mimics features of Charcot-Marie-Tooth neuropathy type $2 \mathrm{~B}$ in Drosophila. Neurobiol Dis $\underline{65}, 211-219$

Karlsson U, Schultz RL (1965): Fixation of the central nervous system from electron microscopy by aldehyde perfusion. J Ultrastruct Res $\underline{12}, 160-186$

Kent C, Carman GM (1999): Interactions among pathways for phosphatidylcholine metabolism, CTP synthesis and secretion through the Golgi apparatus. Trends Biochem Sci 느, 146-150

Khajavi M, Shiga K, Wiszniewski W, He F, Shaw CA, Yan J, Wensel TG, Snipes GJ, Lupski JR (2007): Oral curcumin mitigates the clinical and neuropathologic phenotype of the Trembler-J mouse: a potential therapy for inherited neuropathy. Am J Hum Genet $\underline{81}$, 438-53

Klein D, Groh J, Wettmarshausen J, Martini R (2014): Nonuniform molecular features of myelinating Schwann cells in models for CMT1: Distinct disease patterns are associated with NCAM and c-Jun upregulation. Glia $\underline{62}, 736-750$

Lazzarini RL, Griffin JW, Lassman H, Nave KA, Miller RH, Trapp BD (Hrsg.): Myelin biology and disorders. 1. Auflage; Elsevier Academic Press, San Diego 2004 
Liang G, Cline GW, Macica CM (2007): IGF-1 stimulates de novo fatty acid biosynthesis by Schwann cells during myelination. Glia $\underline{55}, 632-641$

Luft JH (1961): Improvements in epoxy resin embedding methods. J Biophys Biochem Cytol $\underline{9}, 409-414$

Meyer zu Hörste G, Prukop T, Liebetanz D, Mobius W, Nave, KA, Sereda MW (2007): Antiprogesterone therapy uncouples axonal loss from demyelination in a transgenic rat model of CMT1A neuropathy. Ann Neurol $\underline{61}, 61-72$

Mullis K, Faloona F, Scharf S, Saiki R, Horn G, Erlich H (1986): Specific enzymatic amplification of DNA in vitro: the polymerase chain reaction. Cold Spring Harb Symp Quant Biol 51, 263-273.

Nicks J, Lee S, Harris A, Falk DJ, Todd AG, Arredondo K, Dunn WA Jr, Notterpek L (2014): Rapamycin improves peripheral nerve myelination while it fails to benefit neuromuscular performance in neuropathic mice. Neurobiol Dis $\underline{70}, 224-236$

Notterpek L, Ryan MC, Tobler AR, Shooter EM (1999): PMP22 accumulation in aggresomes: implications for CMT1A pathology. Neurobiol Dis $\underline{6}, 450-460$

O'Brien JS, Sampson EL, Stern MB (1967): Lipid composition of myelin from the peripheral nervous system. J Neurochem 14, 357-365 
Pareyson D, Marchesi C (2009): Diagnosis, natural history, and management of Charcot-Marie-Tooth disease. Lancet $\underline{8}, 654-667$

Passage E, Norreel JC, Noack-Fraissignes P, Sanguedolce V, Pizant J, Thirion X, Robaglia-Schlupp A, Pellissier JF, Fontés M (2004): Ascorbic acid treatment corrects the phenotype of a mouse model of Charcot-Marie-Tooth disease. Nat Med 10, 396-401

Reynolds ES (1963): The use of lead citrate at high pH as an electron-opaque stain in electron microscopy. J Cell Biol 17, 208-212

Richardson KC, Jarett L, Finke EH (1960): Embedding in epoxy resins for ultrathin sectioning in electron microscopy. Stain Technol $\underline{35}, 313-323$

Sahenk Z, Nagaraja HN, McCracken BS, King WM, Freimer ML, Cedarbaum JM, Mendell JR (2005): NT-3 promotes nerve regeneration and sensory improvement in CMT1A mouse models and in patients. Neurology, $\underline{65}, 681$ 689

Saher G, Brügger B, Lappe-Siefke C, Möbius W, Tozawa RI, Wehr MC, Wieland F, Ishibashi F, Nave KA (2005): High cholesterol level is essential for myelin membrane growth. Nat Neurosci $\underline{8}, 468-475$

Saher G, Rudolphi F, Corthals K, Ruhwedel T, Schmidt KF, Löwel S, Dibaj P, Barette B, Möbius W, Nave KA (2012): Therapy of Pelizaeus-Merzbacher disease in mice by feeding a cholesterol-enriched diet. Nat Med 18, 1130-1135 
Sereda MW, Griffiths I, Pühlhofer A, Stewart H, Rossner MJ, Zimmermann F, Magyar JP, Schneider A, Hund E, Meinck HM et al. (1996): A transgenic rat model of Charcot-Marie-Tooth disease. Neuron 16, 1049-1060

Sereda MW, Meyer zu Hörste G, Suter U, Uzma N, Nave KA (2003): Therapeutic administration of progesterone antagonist in a model of CharcotMarie-Tooth disease (CMT1A). Nat Med $\underline{9}, 1533-1537$

Simons M, Trotter J (2007): Wrapping it up: the cell biology of myelination. Curr Opin Neurobiol 17, 533-540

Simons M, Krämer EM, Macchi P, Rathke-Hartlieb S, Trotter J, Nave KA, Schulz JB (2002): Overexpression of the myelin proteolipid protein leads to accumulation of cholesterol and proteolipid protein in endosomes/lysosomes implications for Pelizaeus-Merzbacher disease. J Cell Biol 157, 327-336

Szigeti K, Lupski JR (2009): Charcot-Marie-Tooth disease. Eur J Hum Genet $\underline{17}, 703-710$

Verheijen MH, Chrast R, Burrola P, Lemke G (2003): Local regulation of fat metabolism in peripheral nerves. Genes Dev 17, 2450-2464

Yao JK (1982): Increased polyunsaturated fatty acids in developing and regenerating peripheral nerve. Biochim Biophys Acta 712, 542-546 
Danksagung

\section{Danksagung}

Für die Ermöglichung dieser Arbeit danke ich hiermit dem Max-Planck-Institut für Experimentelle Medizin in Göttingen. 